\title{
Mitoxantrone for multiple sclerosis (Review)
}

\author{
Martinelli Boneschi F, Vacchi L, Rovaris M, Capra R, Comi G
}

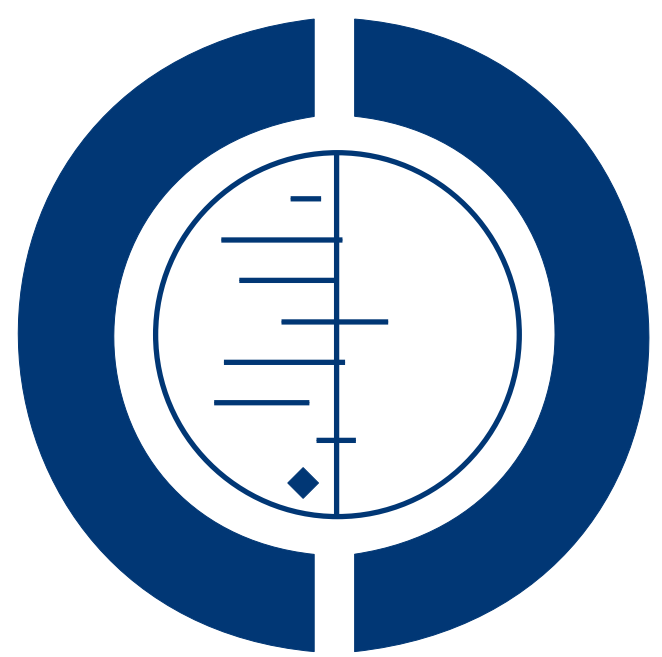

\section{THE COCHRANE COLLABORATION ${ }^{\circledR}$}

This is a reprint of a Cochrane review, prepared and maintained by The Cochrane Collaboration and published in The Cochrane Library 2013, Issue 5

http://www.thecochranelibrary.com

\section{WILEY}


TABLE OF CONTENTS

HEADER

ABSTRACT

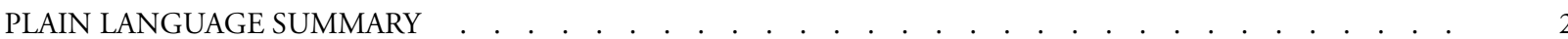

BACKGROUND . . . . . . . . . . . . . . . . . . . . . . . . . . . . . . . . . . . . . . . . .

OBJECTIVES . . . . . . . . . . . . . . . . . . . . . . . . . . . . . . . . . . . . . . . . 44

METHODS . . . . . . . . . . . . . . . . . . . . . . . . . . . . . . . . . . . . . . . 4.4

RESULTS . . . . . . . . . . . . . . . . . . . . . . . . . . . . . . . . . . . 6

Figure 1. . . . . . . . . . . . . . . . . . . . . . . . . . . . . . . . . . . . . . 47

Figure 2. . . . . . . . . . . . . . . . . . . . . . . . . . . . . . . . . . . . . . . 11

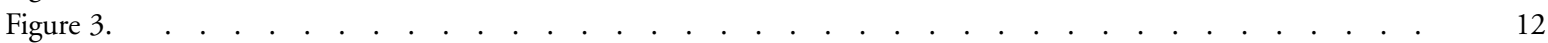

DISCUSSION . . . . . . . . . . . . . . . . . . . . . . . . . . . . . . . . . . . . . . .

AUTHORS' CONCLUSIONS . . . . . . . . . . . . . . . . . . . . . . . . . . . . . . . . . . . . . . . 19

ACKNOWLEDGEMENTS . . . . . . . . . . . . . . . . . . . . . . . . . . . . . . . . . . . . . . .

REFERENCES . . . . . . . . . . . . . . . . . . . . . . . . . . . . . . . . . . . . . . 20

CHARACTERISTICS OF STUDIES . . . . . . . . . . . . . . . . . . . . . . . . . . . . . . . . . . . . . .

DATA AND ANALYSES . . . . . . . . . . . . . . . . . . . . . . . . . . . . . . . . . . . 33

Analysis 1.1. Comparison 1 Mitoxantrone versus placebo: primary outcomes, Outcome 1 Patients with 6-month confirmed disability progression at 2 years. $\quad . \quad$. . . . . . . . . . . . . . . . . . . . . . . . . . . . . . . . . . .

Analysis 1.2. Comparison 1 Mitoxantrone versus placebo: primary outcomes, Outcome 2 Post-hoc analysis: Patients with 3- or 6-month confirmed disability progression.

Analysis 1.3. Comparison 1 Mitoxantrone versus placebo: primary outcomes, Outcome 3 Patients who withdrew from the study because of major side effects of the drug.

Analysis 2.1. Comparison 2 Mitoxantrone versus placebo: secondary outcomes, Outcome 1 Patients with no relapses at 6 months/ 1 year.

Analysis 2.2. Comparison 2 Mitoxantrone versus placebo: secondary outcomes, Outcome 2 Mean change in disability (EDSS).

Analysis 2.3. Comparison 2 Mitoxantrone versus placebo: secondary outcomes, Outcome 3 Patients with no relapses at 2 years. .

Analysis 2.4. Comparison 2 Mitoxantrone versus placebo: secondary outcomes, Outcome 4 Annualized relapse rate. .

Analysis 2.5. Comparison 2 Mitoxantrone versus placebo: secondary outcomes, Outcome 5 Number of MRI active lesions.

Analysis 2.6. Comparison 2 Mitoxantrone versus placebo: secondary outcomes, Outcome 6 Number of patients with active lesions.

Analysis 3.1. Comparison 3 Mitoxantrone versus placebo: adverse events, Outcome 1 Amenorrea. . . . . . . . . .

Analysis 3.2. Comparison 3 Mitoxantrone versus placebo: adverse events, Outcome 2 Nausea/Vomiting. . . . . . . . 45

Analysis 3.3. Comparison 3 Mitoxantrone versus placebo: adverse events, Outcome 3 Alopecia. . . . . . . . . . 45

Analysis 3.4. Comparison 3 Mitoxantrone versus placebo: adverse events, Outcome 4 Urinary tract Infections. $\quad$. $\quad 46$

Analysis 3.5. Comparison 3 Mitoxantrone versus placebo: adverse events, Outcome 5 Respiratory tract infections. . 47

Analysis 3.6. Comparison 3 Mitoxantrone versus placebo: adverse events, Outcome 6 Headhache. . . . . . . . . . 48

Analysis 4.1. Comparison 4 Mitoxantrone versus placebo: abnormal laboratory values, Outcome 1 Leucopenia. $\quad$. $\quad 48$

Analysis 4.2. Comparison 4 Mitoxantrone versus placebo: abnormal laboratory values, Outcome 2 Anemia. $\quad . \quad$. . 49

ADDITIONAL TABLES . . . . . . . . . . . . . . . . . . . . . . . . . . . . . . . . . . . . . . . . . . . . . 49

APPENDICES . . . . . . . . . . . . . . . . . . . . . . . . . . . . . . . . . . . . . . 50

WHAT'S NEW . . . . . . . . . . . . . . . . . . . . . . . . . . . . . . . . . . . . . 50

HISTORY . . . . . . . . . . . . . . . . . . . . . . . . . . . . . . . . . . . . . . . . . 51

CONTRIBUTIONS OF AUTHORS . . . . . . . . . . . . . . . . . . . . . . . . . . . . . . . . . . . . 51

DECLARATIONS OF INTEREST . . . . . . . . . . . . . . . . . . . . . . . . . . . . . . . . . . . . . . . . 52

DIFFERENCES BETWEEN PROTOCOL AND REVIEW . . . . . . . . . . . . . . . . . . . . . . . . . . . . . . . 52

INDEX TERMS . . . . . . . . . . . . . . . . . . . . . . . . . . . . . . . . . 52

Mitoxantrone for multiple sclerosis (Review)

Copyright $\odot 2013$ The Cochrane Collaboration. Published by John Wiley \& Sons, Ltd. 


\title{
[Intervention Review]
}

\section{Mitoxantrone for multiple sclerosis}

\author{
Filippo Martinelli Boneschi ${ }^{1}$, Laura Vacchi ${ }^{2}$, Marco Rovaris $^{3}$, Ruggero Capra ${ }^{4}$, Giancarlo Comi ${ }^{5}$ \\ ${ }^{1}$ Department of Neurology, INSPE - San Raffaele Scientific Institute, Milano, Italy. ${ }^{2}$ Institute of Experimental Neurology (INSPE), \\ Scientific Institute and University Ospedale San Raffaele, Milano, Italy. ${ }^{3}$ U.O. Sclerosi Multipla, I.R.C.S.S. S. Maria Nascente - \\ Fondazione Don Gnocchi, Milano, Italy. ${ }^{4}$ Spedali Civili, Brescia, Italy. ${ }^{5}$ Department of Neurology, San Raffaele Hospital, Milano, Italy \\ Contact address: Filippo Martinelli Boneschi, Department of Neurology, INSPE - San Raffaele Scientific Institute, Via Olgettina, 48, \\ Milano, 20131, Italy. filippo.martinelli@hsr.it.
}

Editorial group: Cochrane Multiple Sclerosis and Rare Diseases of the Central Nervous System Group.

Publication status and date: Stable (no update expected for reasons given in 'What's new'), published in Issue 10, 2013.

Review content assessed as up-to-date: 30 May 2013.

Citation: Martinelli Boneschi F, Vacchi L, Rovaris M, Capra R, Comi G. Mitoxantrone for multiple sclerosis. Cochrane Database of Systematic Reviews 2013, Issue 5. Art. No.: CD002127. DOI: 10.1002/14651858.CD002127.pub3.

Copyright (C) 2013 The Cochrane Collaboration. Published by John Wiley \& Sons, Ltd.

\begin{abstract}
A B S T R A C T

\section{Background}

Mitoxantrone (MX) has been shown to be moderately effective in reducing the clinical outcome measures of disease activity in multiple sclerosis (MS) patients.
\end{abstract}

This is an update of the Cochrane review "Mitoxantrone for multiple sclerosis" (published on Cochrane Database of Systematic Reviews 2013, Issue 5).

\section{Objectives}

The main objective was to assess the efficacy and safety of MX compared to a control group in relapsing-remitting (RRMS), progressive relapsing (PRMS) and secondary progressive (SPMS) MS participants.

\section{Search methods}

We searched the Cochrane Multiple Sclerosis and Rare Diseases of the Central Nervous System Group Specialised Register (23 May 2013). We also undertook handsearching and contacted trialists and pharmaceutical companies.

\section{Selection criteria}

Randomised, double-blinded, controlled trials (RCTs) comparing the administration of MX versus placebo or MX plus steroids treatment versus placebo plus steroids treatment were included.

\section{Data collection and analysis}

The review authors independently selected articles for inclusion. They independently extracted clinical, safety and magnetic resonance imaging (MRI) data, resolving disagreements by discussion. Risk of bias was evaluated to assess the quality of the studies. Treatment effect was measured using odds ratios (OR) with $95 \%$ confidence intervals (CI) for the binary outcomes and mean differences (MD) with $95 \%$ CI for the continuous outcomes. If heterogeneity was absent, a fixed-effect model was used.

Mitoxantrone for multiple sclerosis (Review)

Copyright () 2013 The Cochrane Collaboration. Published by John Wiley \& Sons, Ltd. 


\section{Main results}

Three trials were selected and 221 participants were included in the analyses. MX reduced the progression of disability at two years follow-up (proportion of participants with six months confirmed progression of disability (OR 0.30, 95\% CI 0.09 to 0.99 and MD $0.36,95 \%$ CI- 0.70 to $-0.02 ; \mathrm{P}=0.04)$. Significant results were found regarding the reduction in annualised relapse rate (MD -0.85 , $95 \% \mathrm{CI}-1.47$ to $-0.23 ; \mathrm{P}=0.007)$, the proportion of patients free from relapses at one year $(\mathrm{OR} 7.13,95 \% \mathrm{CI} 2.06$ to $24.61 ; \mathrm{P}=$ 0.002) and two years (OR 2.82, 95\% CI 1.54 to 5.19; $\mathrm{P}=0.0008)$, and the number of patients with active MRI lesions at six months or one year only (OR $0.24,95 \%$ CI 0.10 to $0.57 ; \mathrm{P}=0.001$ ).

Side effects reported in the trials (amenorrhoea, nausea and vomiting, alopecia and urinary tract infections) were more frequent in treated patients than in controls, while no major adverse events have been reported. These results should be considered with caution because of the limited number of included subjects the heterogeneous characteristics of included trials in term of drug dosage, inclusion criteria and quality of included trials. Moreover, it was not possible to estimate the long-term efficacy and safety of MX.

\section{Authors' conclusions}

MX shows a significant but partial efficacy in reducing the risk of MS progression and the frequency of relapses in patients affected by worsening RRMS, PRMS and SPMS in the short-term follow-up (two years). No major neoplastic events or symptomatic cardiotoxicity related to MX have been reported; however studies with longer follow-up (not included in this review) have raised concerns about the risk of systolic disfunction and therapy-related acute leukaemias, occurring in about $12 \%$ and $0.8 \%$ of MX-treated patients respectively.

MX should be limited to treating patients with worsening RRMS and SPMS and with evidence of persistent inflammatory activity after a careful assessment of the individual patients' risk and benefit profiles. Assessment should also consider the present availability of alternative therapies with less severe adverse events.

\section{PLAIN LANGUAGE SUMMARY}

\section{The use of the immunosuppressive drug mitoxantrone (MX) in people with multiple sclerosis (MS)}

This is an update of the Cochrane review "Mitoxantrone for multiple sclerosis" (published on Cochrane Database of Systematic Reviews 2013, Issue 5).

MX is considered an immune-mediated chronic disorder of the central nervous system (CNS), characterized by multiple areas of inflammation and demyelination. Several drugs such as steroids as well as immunomodulant and immunosuppressive agents have been used to treat the disease course. Among them, MX, an immunosuppressive agent widely used for treatment of breast cancer and leukaemia, has been tested in MS individuals. Two hundred seventy-five articles were identified by the search strategy up to May 2013. Three trials contributed to this review, comprising a total of 221 participants. Data show that MX was moderately effective in reducing the risk of MS progression and the frequency of relapses in short-term follow-up (up to two years) of patients affected by worsening relapsing-remitting MS (RRMS), progressive relapsing MS (PRMS) and secondary progressive MS (SPMS). However, caution must be exercised when interpreting these results because of the heterogeneous characteristics and quality of the included trials, which are different in terms of treatment schedules and types of enrolled patients.

The most frequent adverse effects were nausea and vomiting, alopecia, urinary tract infections and transitory leucopenia; 35\% of MXtreated female participants developed transitory amenorrhoea, and almost 15\% developed a persistent amenorrhoea which was still present at the end of the follow-up period. Data from studies with longer follow-up and out of included trials have raised concerns about cardiotoxicity and acute leukaemias, occurring in about $12 \%$ and $0.8 \%$ of MX-treated patients respectively.

For these reasons, MX treatment should be limited to patients with worsening RRMS and SPMS after a careful assessment of the individual patients' risk and benefit profiles, also considering the present availability of alternative therapies with less severe adverse events. Moreover, MX-treated patients need to be followed-up after the end of treatment to control the risk of serious adverse events.

Mitoxantrone for multiple sclerosis (Review) 


\section{B A C K G R O U N D}

\section{Description of the condition}

Multiple sclerosis (MS) is an immune-mediated chronic disorder of the central nervous system (CNS) characterized by multiple areas of inflammation and demyelination. Neuropathological evidence indicates that activated $\mathrm{T}$ cells enter the CNS across small veins and produce an immune cascade effect, causing localized areas of myelin, oligodendrocyte and axonal loss. The resulting lesions (called plaques) accumulate over time and determine the progressive increase of disease burden.

MS is among the commonest causes of neurological disability in young people and it has an annual incidence ranging from 2 to 10 cases $/ 100,000$ persons/year. A north-south gradient was found, with lower incidence being closer to the equator (Compston 1998). Its clinical manifestations typically occur between 20 and 40 years of age with symptoms and signs involving different CNS regions (optic nerve, brainstem, cerebellum, cerebral hemispheres, spinal cord) (Compston 1998).

There are different clinical phenotypes of MS. About $85 \%$ of MS patients have an initial relapsing-remitting (RR) form, characterized by acute attacks or relapses with the appearance of neurological deficits followed by a partial or complete remission. By definition, an attack should last for more than 24 hours. Between attacks patients are clinically stable. Among RRMS patients, $20 \%$ have a milder form of the disease, defined as benign MS. These patients are fully functional after 15 years from disease onset. After a RR course of variable duration (Weinshenker 1989), 50\% within 10 years from the disease onset, and more than $80 \%$ within 25 years, enter the secondary progressive (SP) form. This is characterized by a slow progression of the neurological disability. Fifteen per cent of MS patients have a primary progressive form (PP), characterized from the onset by a slow worsening of neurological deficits without experiencing attacks. A classification of MS phenotypes (Lublin 1996) includes another form, named progressive relapsing (PR) MS, which is characterized by a progressive course from the beginning of the disease with relapses and continuing progression between relapses.

\section{Description of the intervention}

Although the etiology of MS is unknown, there are some available treatments to cure its manifestations.

- High doses of steroids are used to speed up the recovery from acute relapses.

- Interferon (IFN) beta-1a, interferon (IFN) beta-1b and glatiramer acetate (GA) are used to reduce the attack rate, the magnetic resonance imaging (MRI)-measured disease activity of frequency of enhancing lesions, and the increase of MRI lesion burden in
RRMS patients. Although they have recently been licensed in several European countries as drugs to treat progressive MS patients, their long-term efficacy is still debatable and additional data are needed (Filippini 2003).

- More recently, a monoclonal antibody (natalizumab) and the first oral treatment (fingolimod) have been licensed to be used in RRMS (Kieseier 2011).

- Several drugs are used to treat symptoms related to MS such as spasticity, ataxia, fatigue, pain, urinary disturbances, etc. (Thompson 2010).

- As regards mitoxantrone, it was approved in 2000 by the United States Food and Drug Administration (FDA 1999) for the treatment of progressive MS. The indication was "for reducing neurological disability and/or the frequency of clinical relapses in patients with secondary progressive, progressive relapsing or worsening relapsing-remitting multiple sclerosis". In March 2005, the FDA added a 'black box' warning about cardiotoxicity and therapy-related acute leukaemia (TRAL) and in July 2008 recommended that MX-treated patients receive annual cardiac function testing after MX therapy. Moreover, there are additional concerns about the risk of TRAL, as shown by different longterm follow-up studies (http://www.fda.gov/Drugs/DrugSafety/ PostmarketDrugSafetyInformationforPatientsandProviders/ ucm126445.htm, accessed 20 th August 2012).

\section{How the intervention might work}

Mitoxantrone (MX) is a cytotoxic agent of the anthracenedione family, which acts by intercalating with DNA and inhibiting the topoisomerase II enzyme activity for DNA repair (Durr 1983; Smith 1983). It has immunosuppressive properties by reducing the number of $\mathrm{B}$ cells, inhibiting $\mathrm{T}$ helper cell function, and augmenting $\mathrm{T}$ cell suppressor activity. MX is widely used for treatment of breast cancer and leukaemias. It is nowadays approved in 50 different countries for treatment of severe tumours, including advanced breast cancer, hepatoma, non-Hodgkin lymphoma and others.

A well known side effect is cardiotoxicity, seen in 3\% to $4 \%$ of patients treated with high cumulative doses of MX, and a persistent decrease of circulating white cells and platelets. However, this drug shows considerably less acute toxicity (nausea, vomiting, alopecia) than other chemotherapy agents (Sibley 1996).

The first observations of the efficacy of MX in MS derived from studies performed in experimental allergic encephalomyelitis (EAE), which represents the animal model of MS, showing that intravenous administration of the drug was able to suppress disease evolution (Lublin 1987). MX efficacy in MS can be explained by different effects on the immune system:

1) down regulation of CD4 cells (Fidler 1985);

2) suppressive effects on different $B$ cell functions, such as antigen presentation, antibody-dependent demyelination, and comple- 
ment mediated myelinolysis (Fidler 1986a; Levine 1986; Mustafa 1993);

3) inhibition of the demyelinating activity of macrophages ( Watson 1991);

4) proliferation of nonspecific suppressor T cells (Fidler 1986b). Compared with other immunosuppressants, MX determines a broad immunosuppression on all the main components of the immune reactions, namely B cells, T cells and macrophages. Moreover, $\mathrm{MX}$ is a 'long-acting' immunosuppressor as it has a long-term elimination phase with a half-life of nine days, and it is largely sequestered for an extended period of time (up to one month) in the deep tissue compartment and is slowly released (Ehninger 1986).

\section{Why it is important to do this review}

The experimental evidence of MX efficacy on EAE models was confirmed in several unblinded pilot clinical studies without randomisation (Capra 1993; Gonsette 1990; Kappos 1990; Krapf 1995; Mauch 1999; Noseworthy 1993; Rees 1998), not considered in the present review.

Despite the evidence of cardiotoxicity $(-12 \%$ risk of systolic dysfunction) and leukaemia ( $-0.8 \%$ risk of TRAL) related to MX administration, a recent evidence report drafted by the American Academy of Neurology (Marriott 2010) supported the efficacy of the drug in RRMS, SPMS and PRMS and suggested including it among the available drugs.

Thus, a systematic review is warranted to verify the effectiveness and safety of MX use in clinical practice for MS patients.

\section{O B J E C T I V E S}

The objective of the review was to determine the efficacy and safety of mitoxantrone as an immunosuppressive therapy in patients affected by RR, PR and SP MS. The primary hypotheses to be tested were whether MX treatment:

1) is effective in reducing progression of disability;

2) has an acceptable safety profile.

The secondary hypotheses to be tested were whether MX is effective in:

1) reducing the relapse rate;

2) improving patient's related quality of life;

3) reducing the number of brain magnetic resonance imaging (MRI) 'active' lesions;

4) reducing the accumulation of brain MRI lesion burden.

\section{METHODS}

\section{Criteria for considering studies for this review}

\section{Types of studies}

Randomised, double-blinded, controlled trials (RCTs) comparing the administration of MX versus placebo or MX plus steroids treatment versus placebo plus the same additive therapy (that is, steroids) were included. Uncontrolled or non-randomised trials were excluded. Trials in which two different active agents were compared (for example, mitoxantrone versus interferon or glatiramer or methylprednisolone) were excluded.

\section{Types of participants}

Adult patients with a clinically definite diagnosis of MS, according to Poser (Poser 1983) or McDonald criteria and further revisions (McDonald 2001; Polman 2005; Polman 2011) criteria, affected by a RR, SP or PR course regardless of age, sex, degree of disability and duration of the disease. We excluded patients with primary progressive (PP) MS.

\section{Types of interventions}

MX versus placebo or MX plus steroids treatment versus placebo plus steroids.

Any trial was evaluated, independent of dosage, route of administration, frequency of administration and duration of treatment.

\section{Types of outcome measures}

\section{Primary outcomes}

The primary outcome measures were as follows.

1) Number of participants who had confirmed disability progression at one year and after, from the inclusion into the trial. Disability progression was defined as an increase of at least 1 point above the entry score if baseline score $<5.5$, and of at least a halfpoint if baseline score $>5.5$, of the Kurtzke Expanded Disability Status Scale (EDSS) (Kurtzke 1983), assessed in two different and subsequent neurological examinations separated by at least a six month interval free of relapses.*

2) Number of participants who withdrew from the study because of major side effects of the drug, considered as those side effects causing death or hospitalisation of the participant.

* Please note: at the time we assessed the data for this review, we realised that the definitions and measures of disability progression varied between the included trials. Therefore, we decided to perform, in addition to the originally planned analyses, additional analyses accepting the definitions of disability given in the original

Mitoxantrone for multiple sclerosis (Review) 
papers and to include this outcome here, with due allowance for its post hoc nature.

\section{Secondary outcomes}

The secondary outcome measures were:

1) mean change in expanded disability status scale (EDSS) in the allocated treatment groups at one year and longer;

2) patients with no relapses at six months or one year and after;

3) annualised relapse rate at six months or one year and after;

4) mean and standard deviation (SD) for changes in total area or volume on brain MRI scans at six months or one year and longer from the inclusion into the study (Filippi 1998);

5) number of 'active' lesions, defined as the number of T1 enhancing lesions on MRI scans at six months or one year and two years; 6) number of participants with 'active' lesions at six months or one year and longer from the inclusion into the study;

7) frequency of major (cardiotoxicity; major haematological abnormalities) and minor (nausea; vomiting; alopecia; urinary infections) side effects during the follow-up period;

8) abnormal laboratory values.

\section{Search methods for identification of studies}

A systematic search without language restrictions was conducted.

\section{Electronic searches}

The Review Group's Trials Search Co-ordinator searched the Cochrane Multiple Sclerosis and Rare Diseases of the Central Nervous System Group Trials Register (23 May 2013) which, among other sources, contains:

1. The Cochrane Central Register of Controlled Trials (CENTRAL) (recent issue)

2. MEDLINE (PubMed) (1966 to 23 May 2013)

3. EMBASE (Embase.com) (1974 to 23 May 2013)

4. CINAHL (Ebsco host) (1981 to 23 May 2013)

5. LILACS (Bireme) (1982 to 23 May 2013)

6. PEDro (1990 to 23 May 2013)

7. Clinical trials registries (http://clinicaltrials.gov).

8. WHO International Clinical Trials Registry Portal (http:// apps.who.int/trialsearch/)

Information on the Group's Trials Register and details of search strategies used to identify trials can be found in the 'Specialised Register' section within the Cochrane Multiple Sclerosis and Rare Diseases of the Central Nervous System Group's module. The search terms are listed in Appendix 1.

\section{Searching other resources}

a) Reference lists from identified trials and reviews of multiple sclerosis treatment (completed April 2005); b) Handsearch of recent (1996 to 2005) main neurology journals, abstracts of main neurological and multiple sclerosis congresses and symposia (ENS; ECTRIMS) conference proceedings;

c) Contact with pharmaceutical companies producing the drug [Amgen (www.amgen.com/); Merck-Serono (www.merckserono.co.uk/en/index.html)];

d) Contact with authors of selected articles.

\section{Data collection and analysis}

\section{Selection of studies}

Three review authors (FMB, MR, RC), with clinical experience in MS, MRI and the epidemiological field, independently read and selected articles. A senior reader (GC) resolved any disagreement through discussion.

For the most recent update, two review authors (FMB, LV) independently assessed titles and abstracts of studies resulting from the searches and decided which articles to collect. They obtained full copies of all relevant and potentially relevant studies, those appearing to meet the inclusion criteria, and those for which there were insufficient data in the title and abstract to make a clear decision. The two review authors then independently assessed full texts and resolved any disagreement on the eligibility of the included studies through discussion, achieving a final consensus.

\section{Data extraction and management}

Review authors (FMB, LV, MR, RC) independently extracted data from studies meeting the inclusion criteria. Using a standardised data collection form, for each trial they independently extracted data concerning participants, interventions, clinical and MRI outcome measures performed at different follow-up times, frequency, type and severity of side effects. The same review authors evaluated the quality of the trials using the Cochrane Handbook for Systematic Reviews of Interventions. The extracted data were checked for agreement between the reviewer authors and discrepancies were resolved by a joint discussion. The following details were extracted: 1) study design;

2) characteristics of study participants (clinical baseline characteristics, specific inclusion and exclusion criteria, clinical setting);

3) number and distribution of patients who dropped out or withdrew;

4) a full description of the therapeutic intervention;

5) clinical outcome measurement instruments, clinical outcomes and scores (disability or exacerbation) at specified follow-up times; 6) type and the severity of adverse events, and numbers of patients who discontinued treatment because of adverse events.

Review authors also extracted data on the number of participants in the allocated treatment groups and for each outcome event, irrespective of compliance and exclusion from treatment or follow- 
up because of any other reason, in order to perform an intentionto-treat analysis. We contacted authors to clarify data and check for any subsequent data as yet not reported.

\section{Assessment of risk of bias in included studies}

Two review authors (FMB, LV) independently judged trial quality and reported the results of trial quality assessment in the 'Risk of bias' tables according to the Cochrane Handbook for Systematic Reviews of Interventions (Version 5.1.0, Table 8.5.d) (Higgins 2011). Any disagreement was resolved by discussion to reach consensus. The following domains were assessed as 'Low risk', 'Unclear risk' or 'High risk':

1. random sequence generation (selection bias);

2. allocation concealment (selection bias);

3. blinding of outcome assessment (detection bias);

4. incomplete outcome data (attrition bias), defined as 'High risk' when the percentage and reasons for losses to follow-up were unbalanced between arms;

5. other bias.

\section{Measures of treatment effect}

The data analysis was performed using Review Manager software 5 (Review Manager 2013). For each outcome we calculated a weighted treatment effect across trials.

Binary outcomes were analysed calculating odds ratio (OR) and risk difference $(\mathrm{RD})$ for each trial separately at different follow-up periods, with uncertainty in each result expressed using the relative 95\% confidence interval (CI). Thus, results were expressed as a weighted estimate of OR with the relative $95 \%$ CI.

Continuous outcomes were analysed for each trial separately using mean difference (MD) and its standard deviation (SD); MD with the relative $95 \% \mathrm{CI}$ and the mean weighted difference across all trials were considered.

\section{Dealing with missing data}

We attempted to retrieve missing data from the authors of the studies and from the drug companies licensing the drug (MerckSerono).

\section{Assessment of heterogeneity}

Homogeneity between trial results was tested using a standard $\mathrm{Chi}^{2}$ test, and we rejected homogeneity if the $P$ value was $<0.10$. A fixedeffect model approach (Yusuf 1985) was utilised in combining the trial outcomes in case of homogeneity between trials; in case of heterogeneity, a random-effects model was used (DerSimonian 1986).

\section{Data synthesis}

Results were expressed as a weighted estimate of OR with the relative $95 \%$ CI for binary outcomes. For continuous variables, MD with the relative $95 \% \mathrm{CI}$ and mean weighted difference across all trials were considered. In the absence of heterogeneity, a fixedeffect model was used.

\section{Subgroup analysis and investigation of heterogeneity}

Different definitions of disability progression were reported in included studies. Therefore, we decided to perform analysis on disability progression by using two different definitions: six month only confirmed disability progression (pre-planned analysis); either three or six month confirmed disability progression (post hoc analysis).

\section{Sensitivity analysis}

Due to the high rate of dropouts, we decided to perform a sensitivity analysis to explore the effect of withdrawn and lost to followup patients on the major outcomes. The best case scenario (with regards to treatment) assumed that none of the patients who were excluded from the analysis in the MX-treated group had the unfavourable outcome of interest, while all those excluded from the control group did have, and vice versa for the worst case scenario. The likely scenario assumes that all of the placebo and MX-treated participants who were excluded had the outcome of interest.

\section{RES U L T S}

\section{Description of studies}

Salient characteristics of the design, participants, interventions, and outcomes of the studies meeting the inclusion criteria are summarised in the table Characteristics of included studies.

\section{Results of the search}

Two hundred and seventy-five articles were identified by the search strategy, up to 23 May 2013 (Figure 1). Of these, 18 were selected as full papers assessing the efficacy of MX in MS patients. Thirteen studies were excluded and three were included (Edan 1997; Hartung 2002; Millefiorini 1997); the remaining two articles Nadeau 2006 and Krapf 2005 were classified as secondary references of an already included RCT (Hartung 2002). 
Figure I. Flow diagram up to 23 May 2013.

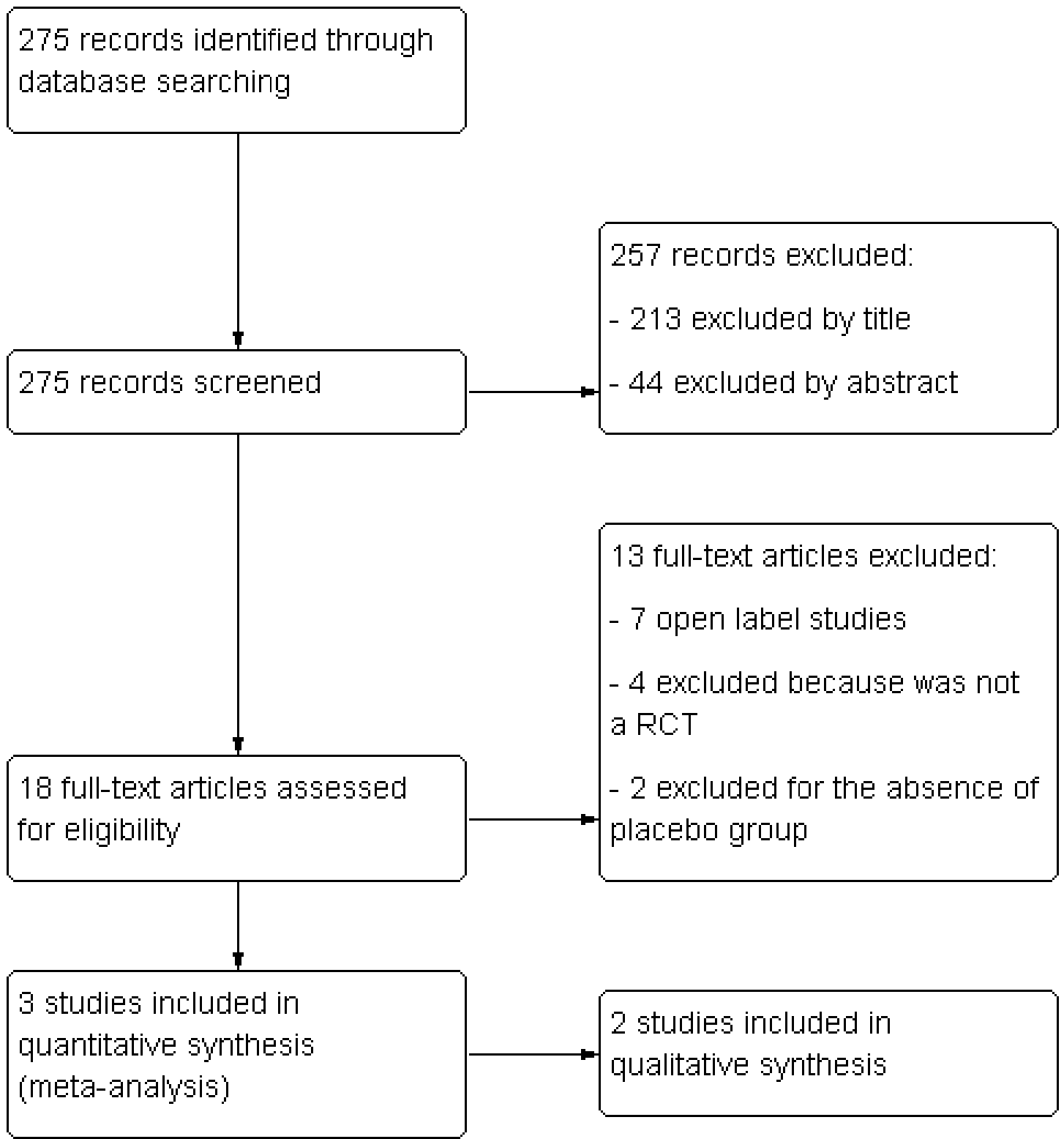


Please note that on August 2012, after reviewing one of the previously included paper (Van de Wyngaert 2001), we decided to exclude this trial from the analysis due to the absence of a clean placebo group (it was treated with steroids, not added in the treatment arm) (Martinelli Boneschi 2013).

\section{Included studies}

Three trials contributed to this review. They were published between 1997 and 2002: Edan 1997, Millefiorini 1997 and Hartung 2002. It is worth mentioning that Edan 1997 was published three years after the end of the recruitment period of the trial, Millefiorini 1997 four years later and Hartung 2002 seven years later. A total of 221 participants contributed to the present review, of whom 111 were assigned to MX and 110 to placebo; Hartung 2002 accounted for $58 \%$ of the total number of participants. Withdrawals and losses to follow-up are shown in Table 1.

\section{Participants}

All studies recruited patients affected by definite MS (McDonald 2001; Poser 1983). The disease course and disability status inclusion criteria were different across studies. In Edan 1997 they were RR participants with at least two exacerbations with sequelae, which corresponds to the definition of worsening relapsing-remitting MS patients, or SP participants with progression of at least 2 points on the EDSS scale in the year before the inclusion; participants had a baseline EDSS lower than 6.0 and at least one MRI active lesion during a baseline observation period two months prior to randomisation. Millefiorini 1997 recruited RR patients with at least two attacks in the previous two years and EDSS between 2.0 and 5.0. Hartung 2002 randomised SP participants, defined as "patients with a gradual progression of disability with or without superimposed clinical relapses", or PR, defined as "patients with a stepwise progression of disability between clinical relapses", who would have been more properly defined as worsening RRMS patients, with progression of at least 1 EDSS point in the preceding 18 months and baseline EDSS between 3.0 and 6.0. Four participants in the Hartung 2002 study were randomised but they never received the treatment.

Disease duration was less than 10 years in Edan 1997 and Millefiorini 1997, while it was not specified in Hartung 2002. The lower age limit was 18 years in all the studies, and was up to 45 years (Millefiorini 1997) or 65 years (Edan 1997; Hartung 2002). Exclusion criteria were similar in all of the studies: pregnancy, use of immunosuppressive drugs in the previous three months, and use of steroids in the previous month. A left ventricular ejection fraction (LVEF) lower than 50\% was also an exclusion criterion in Hartung 2002 and Millefiorini 1997.

\section{Interventions}

In all the studies MX was the active drug, apart from the Edan 1997 study in which MX was given with steroid therapy. The placebo was a sham drug apart from Edan 1997 in which the placebo arm was a short course of steroids $(1 \mathrm{~g} /$ month of intravenous methylprednisolone). However, different dosages and time schedules were used in the studies: Edan 1997 gave MX in 6 pulses of 20 mg every month for 6 months, which corresponded to a total dosage of 120 mg or approximately $72 \mathrm{mg} / \mathrm{m}^{2}$ of body surface over 6 months. Millefiorini 1997 used 12 pulses of $8 \mathrm{mg} / \mathrm{m}^{2}$ body surface every month for 1 year, which corresponded to a total dosage of $96 \mathrm{mg} /$ $\mathrm{m}^{2}$ of body surface over 1 year. Hartung 2002 used 8 pulses of $12 \mathrm{mg} / \mathrm{m}^{2}$ body surface every 3 months for 2 years, which corresponded to a total dosage of $96 \mathrm{mg} / \mathrm{m}^{2}$ body surface over 2 years. Regarding this study, we decided to exclude the intermediate arm of $5 \mathrm{mg} / \mathrm{m}^{2}$ body surface as it used a different dosage from the others (total dosage of $40 \mathrm{mg} / \mathrm{m}^{2}$ body surface over 2 years), which was difficult to compare. This trial allowed an adjustment of the dosage in the case of leucopenia, thrombopenia, infections within three weeks after MX administration, or reduction of the LVEF. As a consequence, the mean cumulative MX dose at the end of the Hartung 2002 study was $82.6 \mathrm{mg} / \mathrm{m}^{2}$ instead of the pre-planned $96 \mathrm{mg} / \mathrm{m}^{2}$.

\section{Outcomes}

In two of the three studies, the primary outcome was a clinical measure, while in Edan 1997 the primary outcome was an MRI measure.

\section{Disease progression}

The disease progression was measured by using two different outcomes: the proportion of participants with confirmed disease progression at the end of the study, and the difference in disability between the end and the beginning of treatment as assessed with the EDSS scale.

With reference to the primary outcome of this review, different definitions were made across the different studies. In Edan 1997, disease progression was defined as a two month confirmed 1.0 point EDSS increase between baseline and the end of the study if the baseline EDSS was $\leq 5.5$, or a 0.5 point EDSS increase if the baseline EDSS was $>5.5$. The authors specified that the increase, if present, was measured for two months running at the end of the study and according to the intention-to-treat (ITT) principle. In Millefiorini 1997, disease progression was defined as an increase of at least 1.0 point on the EDSS scale, which needed to be confirmed at a three month follow-up (personal communication with one of the study authors), irrespective of baseline EDSS. In Hartung

Mitoxantrone for multiple sclerosis (Review) 
2002, disease progression was defined as a six month and three month confirmed deterioration of at least 1 EDSS point between baseline and the end of the study; for the purposes of the present study, we decided to use the six month confirmed progression as a more reliable measure of disease progression.

Analyses on disability progression were performed by using two different definitions: six month only confirmed disability progression (pre-planned analysis) and either three or six month confirmed disability progression (post hoc analysis). As regards the six month confirmed disability progression, only Hartung 2002 provided data for the two year follow-up, while for the post hoc analyses Millefiorini 1997 also provided data for the one and two year follow-up. Edan 1997 was not included in any of these analyses as the duration of the follow-up of six months was considered to be too short an interval for the assessment of disease progression. Looking at the difference in disability between the final and baseline evaluations as measured with the EDSS, Millefiorini 1997 provided data on a subgroup of participants for the one year follow-up, while Millefiorini 1997 and Hartung 2002 provided data for the two year follow-up. Edan 1997 provided data for a six months interval, which was considered too short an interval of time and therefore was not included.

\section{Relapse frequency}

Relapse frequency was assessed by reporting the proportion of participants free from relapses and the annualised relapse rate. Two definitions of relapse, "the occurrence of symptoms of neurological dysfunction lasting more than 48 hours and preceded by stability or improvement for at least 30 days" (Edan 1997); and "the appearance of a new symptom or worsening of an old symptom, attributable to MS, accompanied by a documented new neurological abnormality, lasting more than 48 hours and preceded by stability or improvement for at least 30 days" (Millefiorini 1997), were judged very similar. Hartung 2002 gave a definition only for severe relapses ("the occurrence of new symptoms lasting for longer than 48 hours with a change in functional system score of more than 2 points, or a deterioration of at least 1 point in at least 1 of the 4 following systems: pyramidal, brainstem, cerebellar or visual"), which had to be treated, by protocol, with a five day course of steroids.

Regarding the proportion of participants with no relapses, Edan 1997 and Millefiorini 1997 provided data for the six months to one year follow-up period, and Hartung 2002 and Millefiorini 1997 after two years of follow-up.

With respect to annualised relapse rate, all of the studies provided data at the one year and two year follow-up except for the Edan 1997 study.

Other clinical outcome measures were assessed in Hartung 2002, such as the number of days of hospitalisation due to MS and the use of wheelchair assistance, as well as the quality of life by means of the Stanford health assessment questionnaire (Ramey 1992).

\section{Magnetic resonance imaging (MRI) outcome}

For the present study, we defined the active lesions, and consequently the proportion of participants with active lesions, as lesions which were enhanced after gadolinium injection at the follow-up period. We decided not to include the number of new or enlarged T2 lesions, even if they have to be considered as active lesions, for the following reasons:

1) not all of the studies provided data on that measure;

2) the measurement of T2 lesions is not considered a valid and robust outcome measure as it typically shows a high variability and it is weakly correlated with clinical measures (Filippi 2001);

3 ) in the absence of raw data, we assumed that the new or enlarged T2 lesions were replicated by the enhancing lesions, and that it was sufficient to measure either one of the two measures.

MRI provided the primary outcome measure in Edan 1997. This was the proportion of participants who developed new T1-enhancing lesions on serial monthly gadolinium scans. The number of new enhancing lesions per participant per month and the mean number of new T2-weighted lesions at the end of the trial were used as secondary outcome measures. In Millefiorini 1997, the number of total enhancing lesions at the 12 month follow-up and the number of new or enlarged T2 lesions at the 12 month and 24 month follow-up were measured in a subgroup of patients ( $\mathrm{n}$ $=25$ ). In a subgroup of 110 participants not demographically and clinically different from the original cohort group, Hartung 2002 assessed the numbers of T1 hypointense, T2 hyperintense and gadolinium-enhancing lesions; the T2 lesion load was estimated using a scoring system (Edan 1997; Miller 1991).

For Millefiorini 1997 and Hartung 2002, data were provided by study authors contacts.

\section{Side effects and adverse events}

Side effects and minor and major adverse events were reported in all studies. However, the occurrence of an adverse event was reported when present at least once, irrespective of how many times it appeared. Moreover, it was impossible to know the time of appearance of the adverse event, whether early in the course of therapy or late, because this was not reported in any of the studies; as well as the time of dropping out due to the occurrence of adverse events. Millefiorini 1997 declared that self-reporting was used as adverse events monitoring (judged to be a risk of bias); no information was provided by the other included RCTs.

Echocardiography was performed at the baseline and the end of the study in Edan 1997; at baseline, six and 12 months in Millefiorini 1997; before treatment and once a year in Hartung 2002 (MX was interrupted if the LVEF decreased by more than $10 \%$ from baseline, or below 50\%).

\section{Excluded studies}

From the search strategy (up to May 2013), 13 articles were excluded for the following reasons: seven were open-label studies 
(Capra 1993; Gonsette 1990; Kappos 1990; Kornhuber 1992; Krapf 1995; Noseworthy 1993; Rees 1998), four were observational safety and efficacy studies (Edan 2001; Goodkin 2001; Mauch 1999; Hamzehloo 2007) and one was an RCT with an absent placebo group (Edan 2011).

Regarding open-label studies, they all demonstrated that MX reduced the progression of disability, using different dosages and intervals of administration. Gonsette 1990 used $14 \mathrm{mg} / \mathrm{m}^{2}$ every 3 weeks; Kornhuber 199212 mg/m² every 3 weeks; Kappos 1990 $10 \mathrm{mg} / \mathrm{m}^{2}$ every 3 weeks, Capra 19936 to $10 \mathrm{mg} / \mathrm{m}^{2}$ every 3 months, and Rees $199812 \mathrm{mg} / \mathrm{m}^{2}$ every 3 months. On the contrary, Noseworthy 1993 found that the progression of disability in MX-treated patients at a dosage of $8 \mathrm{mg} / \mathrm{m}^{2}$ every three weeks for a total of seven infusions was not significantly different from that of two historical MS control groups. Krapf 1995 focused on MRI outcomes, and they firstly showed that the total number of MRI-enhancing lesions dramatically decreased after MX therapy, from a total of 169 to 10 after one year and to five after two years of treatment in a series of patients affected by RR (six patients) and SP (four patients). Regarding the observational safety cohort studies (Edan 2001; Goodkin 2001; Mauch 1999; Hamzehloo 2007), they followed up MS patients who had been previously treated with MX to assess the long-term safety and efficacy of the drug (Edan 2001; Mauch 1999), and a registry has been developed (Goodkin 2001) to evaluate and monitor MX long-term cardiotoxicity. Hamzehloo 2007 reported a non-randomised clinical trial 129 on patients (93 females; 108 RRMS and 21 SPMS) who received the treatment regimen of mitoxantrone $12 \mathrm{mg} / \mathrm{m}^{2}$ intravenously every 3 months for 12 months.
Edan 2011 was excluded because a clean placebo arm was lacking (MX monthly plus $1 \mathrm{~g}$ of methylprednisolonefor 6 months followed by IFN for other 27 months versus IFN for 3 years plus $1 \mathrm{~g}$ of methylprednisolone monthly for the first 6 months).

On August 2012, the review authors decided by common consent to exclude a study (Van de Wyngaert 2001) previously included. The reason for exclusion lay in the fact that this RCT didn't meet full criteria for inclusion, because a course of steroids $(1 \mathrm{~g} / \mathrm{month}$ of intravenous methylprednisolone) was added during the first three months of the trial to either arm, and then given only to the placebo group and not concurrently to the treatment group.

Van de Wyngaert 2001 compared 49 patients (28 MX 12 mg versus 21 methylprednisolone) administering agents once a month for the first three months and then every three months until month 32. In this trial, moreover, the disease course of recruited patients was not completely clear, defined as 'relapsing, secondary MS', with a progression of at least 1 point of EDSS in the preceding year and baseline EDSS between 3.0 and 6.0. We believe that they corresponded to the worsening RR, PR or SP course. Disease progression was defined as a 1.0 point EDSS increase if baseline EDSS was $<5.5$ and a 0.5 point increase if baseline EDSS was $\geq 5.5$, and no clinical confirmation seemed to be required. A definition of relapse was not provided.

\section{Risk of bias in included studies}

Risk of bias assessments are summarised in Figure 2 and Figure 3. See the Characteristics of included studies tables for detailed quality assessments of each included study. Overall, no studies were judged as completely free of risk of bias.

Mitoxantrone for multiple sclerosis (Review) 
Figure 2. Methodological quality summary: review authors' judgements about each methodological quality item for each included study.

\begin{tabular}{|c|c|c|c|c|c|c|}
\hline & 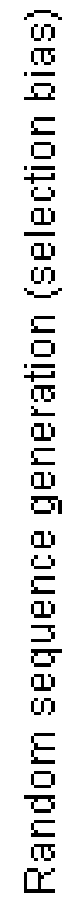 & 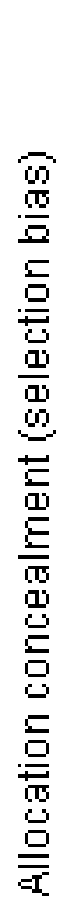 & 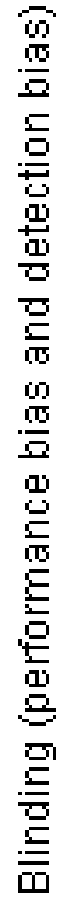 & 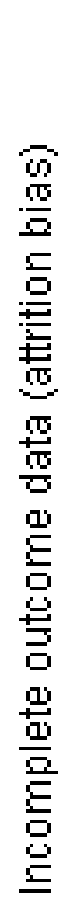 & 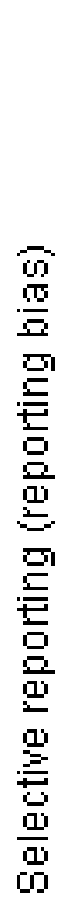 & 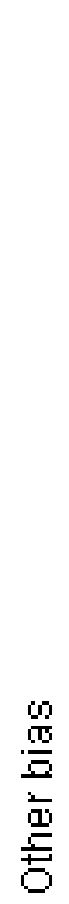 \\
\hline \multicolumn{7}{|l|}{ Edan 1997} \\
\hline Hartung 2002 & + & $?$ & & & & \\
\hline Millefiorini 1997 & 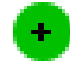 & & & & & \\
\hline
\end{tabular}


Figure 3. Methodological quality graph: review authors' judgements about each methodological quality item presented as percentages across all included studies.

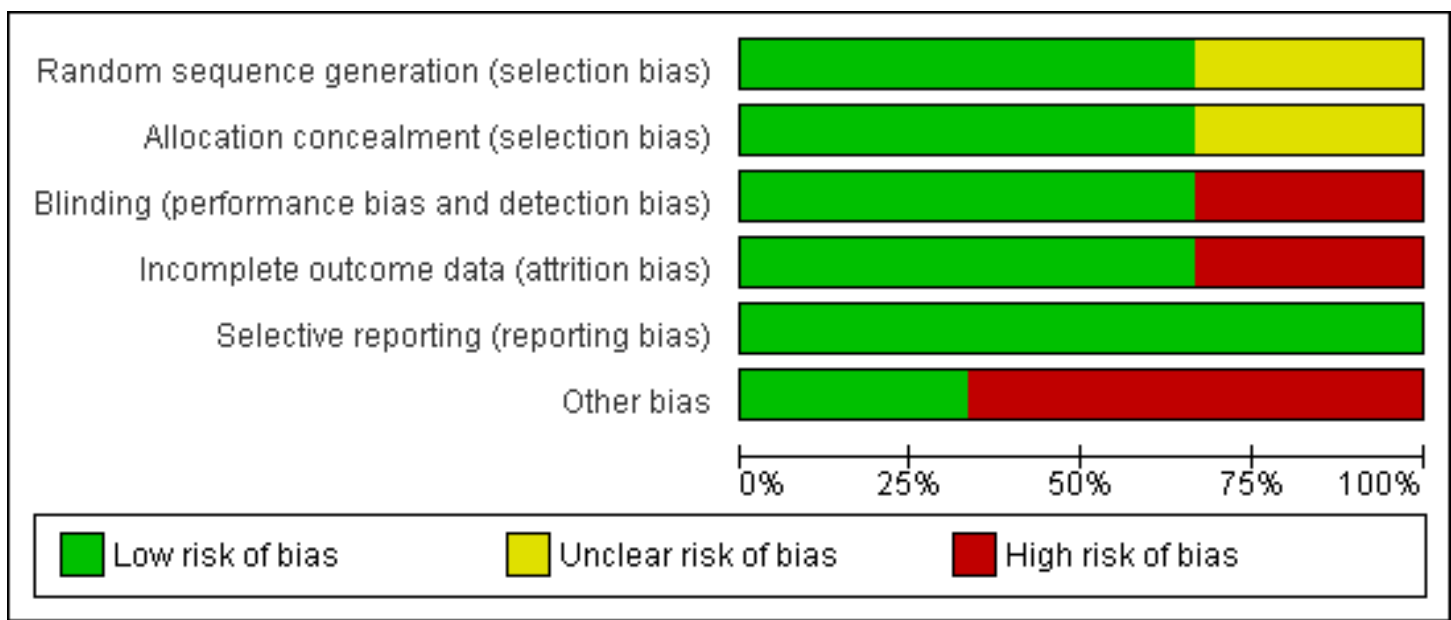

\section{Allocation}

Millefiorini 1997 was judged as 'Low risk' of bias. Edan 1997 didn't provide enough information to judge the method to implement sequence generation, and Hartung 2002 didn't provide a good description of the method used for allocation; these studies were judged as 'Unclear risk' for the respective outcome.

\section{Blinding}

For Hartung 2002 and Millefiorini 1997 blindness was judged adequate, while Edan 1997 was judged at 'High risk' of bias because "neither the patients nor the clinical investigators were blinded during the study"; however, the primary outcome was a MRI measure and the two MRI observers were blinded.

\section{Incomplete outcome data}

In Hartung 2002 and Millefiorini 1997, losses to follow-up were similar in number and the reasons between arms; Edan 1997 was judged at 'High risk' of bias because it had five participants lost to follow-up "due to pronounced clinical worsening", all in the methylprednisolone group.

\section{Selective reporting}

Even if a published protocol was unavailable, no study was judged at 'High risk' of bias because it was clear that the published reports included all expected outcomes, including those pre-specified.

\section{Other potential sources of bias}

Different reasons contributed to judging Edan 1997 and Millefiorini 1997 at 'High risk' of bias (see 'Risk of bias' tables in Characteristics of included studies).

\section{Effects of interventions}

Primary outcomes

\section{1) Number of participants who had confirmed disability progression}

Patients with six months confirmed disability progression over one year: no data were available when considering this definition of confirmed disease progression.

Analysis 1.1 Patients with six months confirmed disability progression over two years: data from 128 participants in Hartung 2002 ( $58 \%$ of the total) were available. An overall $16 / 128$ progressed over two years, 4/63 in the MX group and 12/65 in the placebo group. This corresponded to a sustained overall efficacy of the drug on the progression of disability (OR $0.30,95 \%$ CI 0.09 to 0.99). However, when performing the sensitivity analysis to take into account the four participants who were not included in the intention-to-treat (ITT) analysis (Hartung 2002), the efficacy of the drug disappeared in the worst case and in the likely scenario. Longer follow-up (three years) was available in a subgroup of participants (Hartung 2002): 6/42 (14\%) MX-treated participants versus $16 / 40(40 \%)$ placebo-treated participants had a confirmed 
progression of disease. However, these data were not included in the present review as they were not collected according to an ITT analysis.

Analysis 1.2 Post hoc analysis: patients with three or six month confirmed disability progression: at one year only data from Millefiorini 1997 were available for 51 participants (23\% of the total) of whom eight progressed, two in the MX group and six in the placebo group, leading to an OR of 0.24 (95\% CI 0.04 to $1.33 ; \mathrm{P}=0.1$ ).

At two years, data from two trials (Hartung 2002; Millefiorini $1997)$ and 179 participants ( $81 \%$ of the total) were available for the analysis: 27 participants (12\% of the total) progressed over two years (6 patients in the MX group and 21 in the placebo group). This corresponded to a sustained overall efficacy of the drug on the progression of disability (OR $0.23,95 \%$ CI 0.09 to $0.59 ; \mathrm{P}=0.002$ ). The efficacy was present irrespective of followup duration, dose and frequency of therapy as no heterogeneity across trials was found. When performing the sensitivity analysis to take into account the four participants who dropped out of the Hartung 2002 study and were not considered in the ITT analysis, the efficacy of the drug persisted in all the different scenarios (likely scenario: OR $0.34,95 \%$ CI 0.15 to $0.78 ; \mathrm{P}=0.02$ ).

Finally, Hartung 2002 was the only included RCT that reported data on quality of life. The mean change in the Stanford health assessment questionnaire index was small for the arms over the 24 months of the study. The placebo group mean score increased by 0.26 , with significantly less change observed in the $12 \mathrm{mg} / \mathrm{m}$ 2 mitoxantrone group (0.09; $\mathrm{P}=0.024)$. Thus, more patients in the placebo than in the $12 \mathrm{mg} / \mathrm{m}^{2}$ mitoxantrone group showed deterioration in the health assessment questionnaire index (41 versus $25, \mathrm{P}=0.012$ ), consistent with the lower deterioration measured in this study by the EDSS for the treatment arm.

\section{2) Patients who withdrew from the study because of major side effects of the drug (Analysis 1.3)}

Data were available for all of the studies, including all participants. While Edan 1997 and Millefiorini 1997 declared that no participants were lost to follow-up because of major side effects of the drug, Hartung 2002 reported five treated participants $(3.2 \%$ of the total) versus two $(0.9 \%)$ in the placebo group as losses. Reasons are listed in Table 1. No death, symptomatic cardiac events or tumours were reported during the treatment period.

\section{Secondary outcomes}

\section{Clinical outcomes}

\section{1) Mean change in Expanded Disability Status Scale (Analysis 2.1)}

At six months or one year, a subgroup of participants enrolled in Millefiorini 1997 (11\% of the total) were available for the analysis. The effect of treatment on the patients' disability was not statistically significant (MD - $0.35,95 \%$ CI -0.86 to 0.16 ).

At two years, 175 participants (79.2\% of the total) enrolled in Hartung 2002 and Millefiorini 1997 were available for the outcome. The effect of treatment on the patients' disability was statistically significant (MD - $0.36,95 \% \mathrm{CI}-0.7$ to $-0.02 ; \mathrm{P}=0.04$ ) based on a single study as no dispersion measures were provided for Millefiorini 1997.

\section{2) Patients with no relapses}

Analysis 2.1 At six months or one year, 93 participants (42.1\% of the total) from Edan 1997 and Millefiorini 1997 were available. Forty-five participants did not experience any relapses at six months or one year follow-up (33 MX-treated and 13 placebotreated participants). As the two outcomes were measured at a different follow-up interval, we calculated an OR using a randomeffects model (data not shown); the OR of the two studies was 5.39 (95\% CI 2.21 to $13.15 ; \mathrm{P}=0.0002$ ) suggesting an important role of MX in relapse rate reduction.

Analysis 2.3 At two years, data from 179 participants (81\% of the total) were provided by Millefiorini 1997 and Hartung 2002. Seventy-nine of them didn't have any relapse at the two year follow-up (51 MX-treated patients and 28 placebo-treated patients); the OR was 2.82 (95\% CI 1.54 to 5.19 ; $\mathrm{P}=0.0008)$. When performing the sensitivity analysis to take into account the four participants who dropped out from Hartung 2002 and were not included in the ITT analyses, the efficacy of the drug was confirmed under all the different scenarios (likely scenario: OR 3.11, 95\% CI 1.68 to 5.72; $\mathrm{P}=0.0003$ ).

\section{3) Annualised relapse rate (Analysis 2.4)}

At six months or one year, 217 participants (98.2\% of the total) from the included studies were available for the present outcome. In all of the studies there was a reduction in the annualised relapse rate in MX-treated versus placebo-treated participants. However, as no dispersion measures were available for the other trials, only data from Millefiorini 1997 and 52 participants were used for the analysis, with a MD of -1.02 (95\% CI -1.69 to -0.35 ; $\mathrm{P}=0.003)$. At two years, data from 206 participants were analysed, including Millefiorini 1997 and Hartung 2002. In both studies there was a reduction in the annualised relapse rate in MX-treated versus placebo-treated participants. However, as no dispersion measure was available for Hartung 2002, only Millefiorini 1997 contributed to the estimate of weighted mean difference (MD -0.85 , 95\% CI -1.47 to -0.23 ; $\mathrm{P}=0.007)$. 


\section{Magnetic resonance imaging (MRI) outcomes}

\section{4) Mean and standard deviation (SD) changes in total area or volume on brain MRI scans}

No data were available for this secondary outcome measure in any of the studies. In Hartung 2002 data have been collected but they are still unpublished.

\section{5) Number of 'active' lesions (Analysis 2.5)}

At six months or one year, 62 participants ( $28 \%$ of the total) from Edan 1997 and Millefiorini 1997 provided data for the present outcome. This number of participants represented a subgroup of the original cohort of randomised patients. With regard to Edan 1997, no data were available for the five withdrawn participants, while for Millefiorini 1997 MRI measurements were performed in a subgroup of participants: MD-0.79 (95\% CI -1.68 to 0.09; $\mathrm{P}=0.08)$. There did not appear to be any heterogeneity between studies.

At two years, 70 participants ( $31.7 \%$ of the total) were available for the present outcome from Hartung 2002, reporting 0.03 versus 0.26 in MX- and placebo-treated participants respectively, but no dispersion measures were available to perform a meta-analysis.

\section{6) Number of participants with 'active' lesions (Analysis 2.6)}

At six months or one year, a total of 132 participants $(59.7 \%$ of the total) were included from Edan 1997, Hartung 2002 and Millefiorini 1997 (data provided by study authors). Thirty-five of $132(26.5 \%)$ had active lesions at six months to one year followup (10 MX-treated and 25 placebo-treated participants). MX was found to be effective in reducing the proportion of participants with active lesions (OR $0.24,95 \%$ CI 0.10 to 0.57 ; $\mathrm{P}=0.001$ ). At two years, only participants from the Hartung 2002 study were included; $0 \%$ of MX-treated and $13.5 \%$ of placebo-treated participants had active lesions at two year follow-up, leading to an OR of 0.09 (95\% CI 0.00 to 1.77$)$.

\section{Side effects}

\section{7) Frequency of major and minor side effects}

No heterogeneity was found across the different trials, suggesting that the risk of adverse events was not related to the different treatment regimens used in the different studies.

\section{Amenorrhea and persistent amenorrhoea (Analysis 3.1)}

Amenorrhea was developed during therapy by $35 \%$ of MX-treated female participants and by none of the placebo-treated female participants. For most of the participants the amenorrhoea disappeared after discontinuation of MX therapy; however, in six women ( $12 \%$ of the total) amenorrhoea was still present after the end of treatment: in five participants in Hartung 2002 at the one year follow-up examination after the end of therapy, and in one participant in Edan 1997 at an undefined follow-up visit after the end of therapy. MX-treated female participants had an OR of 22.3 (95\% CI 4.03 to $123.47 ; \mathrm{P}=0.0004$ ) of developing amenorrhoea compared with placebo-treated participants; the risk was higher in Edan 1997 and Hartung 2002 than in the Millefiorini 1997 study. Persistent amenorrhoea had an OR of 8.27 (95\% CI 1.02 to 67.18; $\mathrm{P}=0.05$ ); Millefiorini 1997 declared no events for this outcome.

\section{Symptomatic cardiac events and cardiotoxicity (LVEF reduction below 50\%)}

Regarding cardiotoxicity, there was a quite similar definition across the different trials, which was the decrease of LVEF below 50\%. Edan 1997 and Millefiorini 1997 excluded any case of cardiotoxicity, despite very careful cardiac monitoring, by means of the electrocardiogram and echocardiography. In Hartung 2002, cardiac monitoring was performed at baseline and once a year by means of echocardiography; two MX-treated participants showed a decrease in LVEF to below $50 \%$ at the three year follow-up (namely, one year after the end of the treatment) which was not present at the end of the treatment and one interrupted the treatment after four doses of the drug because of decreased LVEF, but no clinically significant cardiac dysfunction developed in any of the treated participants.

An LVEF reduction, lower than $50 \%$, was observed in $3 / 110$ (2.7\%) of MX-treated participants (Hartung 2002), resulting in discontinuation of therapy in three of them. However, none of the treated participants developed clinically significant cardiac events at least one year after the end of MX treatment.

\section{Nause and vomiting (Analysis 3.2)}

It was reported by 62/110 MX-treated participants (56.3\%) and by $13 / 109$ (13\%) of placebo-treated participants. Therefore, MXtreated participants had a risk which was 14.01 times greater $(95 \%$ CI 6.36 to $30.85 ; \mathrm{P}<0.00001)$ than for placebo-treated participants of developing nausea and vomiting during the administration of the drug. In Hartung 2002 one participant stopped the treatment because of repeated episodes of nausea and vomiting that persisted despite symptomatic treatment and decreases in MX dosage (FDA 1999). 


\section{Alopecia (Analysis 3.3)}

It was reported by 50/110 MX-treated participants (45.5\%) and by 20/109 (18.3\%) placebo-treated participants. MX-treated participants had a 4.65 times greater risk $(95 \%$ CI 2.37 to 9.12 ; $\mathrm{P}<$ $0.0001)$ than placebo-treated participants of developing alopecia during the treatment period.

\section{Urinary tract infections}

(Analysis 3.4)

Twenty-seven of 110 MX-treated participants (24.5\%) and nine of $109(8.3 \%)$ placebo-treated participants experienced urinary tract infection during the trials (OR 3.76, 95\% CI 1.67 to 8.46 ; $\mathrm{P}=0.001)$. One participant in Hartung 2002 interrupted MX treatment because of repeated urinary infections, and another one because of moderate renal insufficiency with evidence of urinary retention and hydronephrosis; this participant recovered after a surgical intervention of sphincterotomy (FDA 1999).

\section{Respiratory tract infections}

(Analysis 3.5)

Forty of 110 MX-treated participants (36.4\%) and 35/109 (32.1\%) placebo-treated participants experienced respiratory tract infections during the trials. As none of the episodes led to discontinuation of treatment, we assumed that all of these episodes were mild to moderate. The difference between the two groups was not statistically significant (OR $1.34,95 \%$ CI 0.72 to $2.50 ; \mathrm{P}=0.35$ ).

\section{Headache}

(Analysis 3.6)

Headache was reported by 7/110 MX-treated participants (6.4\%) and 5/109 (4.6\%) placebo-treated participants. The difference was not statistically significant (OR $1.36,95 \%$ CI 0.44 to $4.24 ; \mathrm{P}=$ $0.59)$.

\section{8) Laboratory side effects}

\section{Leucopenia}

(Analysis 4.1)

It was difficult to measure the exact frequency and severity of the occurrence of leucopenia during MX treatment because of the different definitions across trials and the different time of measurement of white blood cell count after MX administration. In Edan 1997, the white blood cell count was measured at the next monthly injection, and a decrease in leucocytes indicative of a grade two toxicity (according to the WHO) was reported in two MX-treated participants, without any need for dose adjustment. All the MX-treated participants were reported in Edan 1997 to have had a pronounced leucopenia at the so-called 'nadir' period, which was about two weeks after each MX cycle. In Millefiorini 1997, haematological examination was performed on a monthly basis before the next MX cycle and no adverse events were reported. In Hartung 2002, the MX dosage was adjusted according to the white blood cell count; specifically, MX dosage was reduced to $10 \mathrm{mg} / \mathrm{m}^{2}$ for infections occurring within three weeks after an MX infusion if accompanied by a white blood cell count below $2 \times 10^{9} / \mathrm{L}$ or platelet count of less than $50 \times 10^{9} / \mathrm{L}$, or reduced to $8 \mathrm{mg} / \mathrm{m}^{2}$ for infections occurring within three weeks after an MX infusion if accompanied by a white blood cell count below 1 x $10^{9} / \mathrm{L}$ or platelet count of less than $25 \times 10^{9} / \mathrm{L}$. It was, however, unknown how many participants changed the treatment dosage because of that, and the occurrence of leucopenia was reported with no specification of the time of measurement. According to the Food and Drug Administration (FDA) safety review (FDA 1999), in Hartung 2002 adjustments of MX therapy were made in 27 out of 60 participants due to leucopenia occurrence, the mean total MX cumulative dosage was $82.6 \mathrm{mg} / \mathrm{m}^{2}$ (SD 23.1).

Taking into account all of these limitations, 14/83 (16.9\%) MXtreated participants and 0/85 placebo-treated participants developed leucopenia as measured before the administration of the next treatment cycle, leading to an OR of 17.95 (95\% CI 2.35 to 137.00; $\mathrm{P}<0.005)$. Apparently, none of the cases led to an interruption of MX therapy.

\section{Anaemia}

(Analysis 4.2)

Eight out of 83 (10\%) MX-treated participants and 2/85 (2.3\%) placebo-treated participants developed anaemia, resulting in an OR of 4.51 (95\% CI 0.92 to $22.20 ; \mathrm{P}=0.06$ ).

\section{Increased liver enzymes}

Only Edan 1997 and Hartung 2002 reported data on liver enzymes. In Edan 1997 there were no cases of abnormal findings. In the Hartung 2002 article, two different figures were reported: an increase in gamma glutamyl transpeptidase and an increase in aspartate aminotransferase, but it was not known whether they occurred in the same or in different participants. If we postulated that they were different participants, a total of $9 / 62$ (14.5\%) MXtreated participants and 2/64 (3.1\%) placebo-participants showed an increase of hepatic enzymes. It is worth mentioning that two participants (one in Edan 1997 and one in Hartung 2002) of the placebo arm developed hepatitis during the trials. 


\section{DISCUSSIO N}

\section{Summary of main results}

In this review, we addressed four different issues.

\section{1) Is MX therapy effective in reducing the progression of disability and the frequency of clinical attacks?}

Our data confirmed the clinical efficacy of MX on disease progression and relapse frequency in patients affected by MS. Most of the outcomes, either clinical or MRI-related, supported an efficacy of MX.

Regarding the proportion of participants with confirmed progression of disability, due to the different definition of disability progression across studies we decided to perform post hoc analyses additional to the originally planned primary outcome measure. The OR of MX-treated participants versus placebo-treated participants at one year was 0.24 (95\% CI 0.04 to 1.33 ) using the three or six month confirmed definition. As regards the two year follow-up, the OR was 0.30 (95\% CI 0.09 to 0.99 ) using the six month confirmed definition (one study, $58 \%$ of the participants) . While admitting that post hoc analysis, which included a less stringent definition of disability progression, may raise methodological issues, it is worthwhile to mention that the difference in the proportion of patients who experienced disability progression across the two treatment arms was similar and was confirmed by using any of these definitions. Moreover, it is still questionable whether to use the three or six month interval of confirmation of disability progression, even across Cochrane reviews (in Rice 2001: "disability progression is a sustained (3 or 6 months) increase in EDSS of at least 1 point recorded out of exacerbation"; in La Mantia 2010: "progression has been defined as a persistent worsening of at least 1 point in EDSS, recorded out of relapse and confirmed by a follow-up assessment at 6 months"), and we need to be more cautious when aggregating data on unconfirmed disability progression. The use of an interval of three or six months for a confirmation of disability progression does not substantially change the results of the Hartung study (Table 3, page 2022) as the numbers of progressed patients in the MX-and placebo-treated arms were 5/60 versus 14/64 using the three month interval and $4 / 60$ versus $12 / 64$ using the six month interval.

We also performed sensitivity analyses to consider the few patients who dropped out from the studies. In Hartung 2002, it was mentioned that analyses were performed according to an ITT principle (page 2022, second column, line 34). However, four patients (one placebo-treated and three MX-treated) dropped out before receiving any treatment were not included in the ITT analysis, and were therefore considered for the sensitivity analyses. The sensitivity analysis influenced the results at the one year but not at the two year follow-up.
As a general comment, we have also to consider that the EDSS scale is still the most widely used scale to assess disability progression in MS. It has many drawbacks, represented by its poor sensitivity to changes and moderate inter- and intra-observer reliability ( Goodkin 1992). The efficacy of MX in reducing the progression of disability was less evident when the outcome was the difference in EDSS score at the end versus the beginning of treatment, even if a single study was used for the analysis.

MX was effective in reducing the relapse rate (measured as the annualised relapse rate) and in increasing the proportion of patients free from relapses; the efficacy was not modified by the assignment of dropped out patients. From available data, however, it is not possible to ascertain whether the efficacy of MX in reducing the progression of disability is due to a reduction in the frequency of clinical relapses or to other reasons. The clinical efficacy of MX was paralleled by that on MRI-derived outcome measures. When considering MRI measures of inflammatory activity, such as the number of active lesions and the proportion of patients with active lesions (defined as enhancing-lesions on T1 scans), a statistically significant MX efficacy was found for the latter but not for the former measure. On the contrary, it was not possible to explore and aggregate MRI measures of 'neurodegeneration', such as the measurement of brain atrophy, as no data were available from the selected studies.

Admittedly, as a limitation of our meta-analysis, there were many sources of potential heterogeneity across the different trials represented by the following.

a) The types of enrolled patients: in Edan 1997, SP with worsening disability (progression of at least 2 points on EDSS scale in the previous year) and worsening RR (two relapses with sequelae in the previous year) with evidence of MRI inflammatory activity; in Millefiorini 1997, RR with at least two relapses in the previous two years; and in Hartung 2002, SP, PR and worsening RR with evidence of a progression of at least 1 point of EDSS respectively in the preceding 18 and 12 months.

b) The frequency, interval of administration and total dosage of the drug: 6 monthly cycles of $20 \mathrm{mg}$ combined with $1 \mathrm{~g}$ of methylprednisolone in Edan 1997; 12 monthly pulses of $8 \mathrm{mg} / \mathrm{m}^{2}$ of body surface in Millefiorini 1997; 8 pulses every 3 months of 12 $\mathrm{mg} / \mathrm{m}^{2}$ of body surface in Hartung 2002.

c) The addition of steroids to the placebo and active arm in Edan 1997.

However, no major heterogeneity was found according to the statistical methods used, which were planned in the original protocol, in any of the explored outcome measures. This possibly suggests that, at least in the short-term period, none of the above variables acted as effect modifiers or confounders of drug efficacy. We could also argue that the test used (Cochran's Q) is poor in sensitivity when detecting true heterogeneity among studies as being significant, especially when few studies are included in the meta-analysis. Another limitation was the lack of a uniform definition of some of the explored outcome measures across the different studies, es- 
pecially as regards the definition of confirmed progression of disability for which a correct time interval of six months was defined only by Hartung 2002. It is highly warranted to use the same definition of outcome measures across different trials in order to make data from different trials most comparable and available for pooling. Moreover, no data were available from longer follow-up studies that were able to provide information on long-term drug effectiveness. There are some data on MX efficacy at three year follow-up, one year after the end of the trial, in a subgroup of patients from Hartung 2002. Six out of 42 (16\%) MX-treated participants and 16/40 (42\%) placebo-treated participants showed a confirmed progression of disease leading to an OR of $0.25(95 \%$ CI 0.09 to $0.73 ; \mathrm{P}=0.01$ ). However, these analyses were not performed according to an ITT analysis and, therefore, they have limited clinical relevance.

\section{2) Which patients should get MX?}

As previously reported, the selected participants were different across studies, even though no major heterogeneity has been found according to the statistical methods used. It is, however, impossible to establish whether small differences between trials were due to the selected patients or to the different treatment regimens. Gonsette recently suggested that MX should only be used in patients with worsening RR, defined as "RR patients experiencing frequent and disabling relapses likely leading to permanent severe disability", and an SP course with evidence of worsening disability, defined as an increase of at least 1 EDSS point per year (Gonsette 2003).

\section{3) What should be the dosage and frequency of administration of MX?}

No clear indications can be derived from this meta-analysis. A recent review (Gonsette 2003) suggests a treatment regimen with an induction phase $\left(12 \mathrm{mg} / \mathrm{m}^{2}\right.$ every month for 3 months) followed by a maintenance phase $\left(12 \mathrm{mg} / \mathrm{m}^{2}\right.$ every 3 months for 21 months), which seems to be an acceptable trade-off to maintain treatment for 2 years with a reasonable cumulative dose $(120 \mathrm{mg} /$ $\mathrm{m}^{2}$ ). This scheme is supported by the in vivo effect of MX administration on immune cells, which is characterized by a marked immunosuppression (namely, leukopenia $<2000 / \mathrm{mm}^{3}$ or lymphopenia $<1000 / \mathrm{mm}^{3}$ ) after three to four monthly infusions maintained for two years with a subsequent trimonthly administration. The dosage needs to be adjusted according to the haematological profiles shown before the next treatment, as reported in Table 2. It is advisable to adjust the dosage regimen rather than to delay infusions. The treatment regimen suggested by Gonsette 2003 is very similar to that reported in Hartung 2002, which represents the largest trial.

However, it is worthwhile mentioning that another retrospective open-label study (Debouverie 2004) confirmed the effectiveness of the treatment regimen recommended in Edan 1997 of six monthly cycles of $20 \mathrm{mg}$ of MX combined with steroids across worsening RR and SP MS patients. One year after the end of treatment, $44 \%$ of the patients had an EDSS improvement, 39\% remained stable and $17 \%$ had deteriorated.

More recent studies are suggesting the use of this drug as a shortterm induction treatment followed by maintenance immunomodulant treatment in aggressive forms of MS (Edan 2011).

\section{4) Is MX a safe drug?}

According to the conclusions of the FDA safety review, "MX was well tolerated with no deaths, few serious adverse events and few discontinuations of therapy. No previously unrecognised toxicities were observed in these studies. No serious cardiotoxicity events were observed although these studies did not expose patients to cumulative doses above $100 \mathrm{mg} / \mathrm{m}^{2}$. Cardiotoxicity, neutropenia and its sequelae, amenorrhoea, which in some cases may be permanent, and the potential for late occurring leukaemia are the major safety concerns associated with MX use (page 42)". Our metaanalysis confirmed that there were no deaths or symptomatic cardiac events among MX-treated patients. Seven out of $111(6.3 \%$ of the total) MX-treated participants interrupted the treatment for major side effects, of whom one had asymptomatic LVEF lower than $50 \%$, one suffered a major depressive episode, one had repeated episodes of nausea and vomiting, one had repeated urinary infections and one had renal failure. Considering the two out of 110 (2\% of the total) placebo participants who had treatment interrupted, one was due to hepatitis and one had a myocardial infarction.

Thirty-five per cent of female MX-treated participants developed amenorrhoea, and almost $15 \%$ or $12 \%$ ??developed a persistent amenorrhoea which was still present at the end of the study. These data are similar to those reported by Edan et al, who followed up a cohort of $800 \mathrm{MX}$-treated MS participants and found that $6.7 \%$ of women younger than 35 years who received MX at a cumulative dose of $79 \mathrm{mg} / \mathrm{m}^{2}$ developed secondary amenorrhoea (Edan 2001 b). In these cases, a hormonal substitution therapy should be started at the onset of amenorrhoea. As a consequence, patients, especially if of child-bearing age, should be advised of this potential side effect and also on the potential but not fully established teratogenic effects of the drug.

Nausea and vomiting, alopecia and urinary tract infections were more frequent among MX-treated versus placebo-treated participants. There are reports of therapy-related acute leukaemia (TRAL) in MX-treated MS patients, possibly due to a real increment in frequency or to improved surveillance. In contrast to leukaemias associated with alkylating substances such as cyclophosphamide, MX-related acute leukaemias are characterized by a short latency, acute onset and cytogenetic changes similar to de novo leukaemias, such as translocations $11 \mathrm{q} 23,21 \mathrm{q} 22$ or inversion of chromosome 16.Most importantly, they usually respond to therapy (Quesnel 1993). In June 2004, a total of nine MX- 
treated MS patients, four of whom were single case reports, developed TRAL (Brassat 2002; Cattaneo 2003; Delisse 2004; Ghalie 2002a; Goodkin 2003; Heesen 2003; Radu 2002; Voltz 2004). As schematically reported by Voltz (Voltz 2004; page 473, Table 1 ), the onset of leukaemia ranged from three months after the end of MX treatment (Goodkin 2003) to five years (Vicari 1998) across MX-treated MS patients who developed leukaemia, but it mostly occurred within two years following the cessation of treatment. The cumulative dose of MX treatment before the onset of leukaemia ranged from $48 \mathrm{mg} / \mathrm{m}^{2}$ to $120 \mathrm{mg} / \mathrm{m}^{2}$. All of the cases underwent chemotherapy, which was successful in seven out of nine patients but two patients died. There is a recent report of a case of acute promyelocytic leukaemia in a patient who received only $15 \mathrm{mg}$ of MX; however, this patient was affected by breast cancer and, before receiving MX, she had also been treated with radiotherapy (Mistry 2005). A meta-analysis tried to measure the incidence of leukaemia among a cohort of 1378 MX-treated MS participants from three different trials (Ghalie 2002a): the MIMS study (Hartung 2002), a French retrospective study (Edan 2001), and a German retrospective study (Mauch 1999). An incidence proportion of $0.15 \%$ was found after a mean follow-up of 36 months in 1378 patients. This is higher than the proportion of de novo leukaemias in healthy patients, which typically ranges from $0.001 \%$ at 20 years of age to $0.03 \%$ at 70 years of age, but lower than that among patients who underwent combined chemotherapy, including MX, for whom the leukaemia incidence proportion ranges from $2 \%$ to $12 \%$ (Felix 1998). A similar cumulative incidence, $0.21 \%$, was reported by Voltz (Voltz 2004) by pooling the different cases of leukaemia reported in the literature. A registry to evaluate the long-term safety profile of MX has been developed (Goodkin 2001). In the following years, many case series and case reports have identified 56 to 57 cases of TRAL in MX-treated patients (for a summary, see table 2 in Marriott 2010), increasing the incidence of TRAL in MS patients to 33/4076, corresponding to an incidence of $0.81 \%$ and a number needed to harm (NNH) for TRAL development of 123. Most of these cases occurred within a few years of MX treatment. A recent multicentre retrospective cohort study on 3220 MS patients from 40 Italian MS Centers (Martinelli 2011) with a mean follow-up of 49 months revealed 30 cases of acute myelocytic leukaemia (AML), leading to a very similar incidence rate of $0.93 \%(95 \%$ CI $0.60 \%$ to $-1.26 \%)$ and a mortality rate associated with AML of $37 \%$. The median interval from drug start to AML diagnosis was 33 months, ranging from 13 to 84 months. A dose-dependent relationship was revealed by this study, corresponding to a $3 \%$ increase in the risk of AML for every one unit increase in MX cumulative dose. According to this analysis, a cumulative dose between 30 and $60 \mathrm{mg} / \mathrm{m}^{2}$ of body surface was suggested.

Given this evidence, it is particularly important to carefully check leukocytes blood levels before any additional MX cycle. A useful therapeutic scheme is reported in Table 2, where the dosage of the following MX cycle needs to be adjusted according to the haematological profile. Moreover, MX-treated patients should be followed up with complete blood cell counts; the optimal timing of such monitoring being unclear (Marriott 2010).

Cardiotoxicity is the major limiting factor in the long-term administration of MX and sets the maximum cumulative dose at a total of $140 \mathrm{mg} / \mathrm{m}^{2}$ body surface. MX cardiotoxicity appears to be due to the generation of free radicals by the drug which, according to human autopsy tissue concentration measures, are stored in elevated concentrations in the heart. The heart represents the third highest storage deposit of MX after the thyroid and liver (Stewart 1986). Benjamin 1985 examined endomyocardial biopsy specimens from $37 \mathrm{MX}$-treated patients, of whom six were treated with more than $100 \mathrm{mg} / \mathrm{m}^{2}$. Three of them had normal biopsies while the remaining 34 had histological changes resembling those caused by anthracyclines, namely a dilatation of the sarcoplasmic reticulum and myofibrillar dropout. This was, however, defined as minor and was not expected to be of clinical significance in the absence of other cardiac abnormalities. The potential risk of cardiotoxicity could be increased by the fact that a significant proportion of MS patients tend to have impaired cardiac function. Using radionuclide angiocardiography, Olindo 2002 found in a cohort of $40 \mathrm{MS}$ patients that $25 \%$ of them had abnormal LVEFs. A review (Ghalie 2002b) explored the occurrence of cardiotoxicity in $1378 \mathrm{MS}$ patients enrolled in three different studies and who received a mean cumulative dose of MX of $60.5 \mathrm{mg} / \mathrm{m}^{2}$ and were followed-up for a mean of 30 months. Two cases of congestive heart failure $(\mathrm{CHF})$ were reported, one had received a dose of MX higher than $140 \mathrm{mg} / \mathrm{m}^{2}$, leading to an incidence lower than $0.2 \%$. Moreover, a $2.18 \%$ (95\% CI 1.28 to 3.47 ) incidence of an LVEF decrease to below 50\% was found among MX-treated patients. The probability of the event was weakly associated with the total cumulative dosage received $(5 \%$ in patients treated with a total cumulative dosage of MX greater than $100 \mathrm{mg} / \mathrm{m}^{2}$ versus $1.8 \%$ in patients treated with a total cumulative dosage lower than $100 \mathrm{mg} / \mathrm{m}^{2}$ ), which suggests the importance of treating patients with lower dosages than $100 \mathrm{mg} / \mathrm{m}^{2}$ as well as monitoring them. This was previously described by De Castro 1995, who found that a total dose of MX of $96 \mathrm{mg} / \mathrm{m}^{2}$ was not associated with any cardiac toxicity in MS patients. A recent paper reported a significant decline of LVEF among 5/28 (17.8\%) MS patients after three doses of MX and underpins the importance of monitoring these patients carefully (Avasarala 2003).

More recent studies have reported the occurrence of cardiotoxicity in MX-treated patients (for a summary, see table 1 in Marriott $2010)$ leading to an incidence rate of $12 \%(83 / 716)$ for decreased LVEF and of $0.4 \%(3 / 716)$ for congestive heart failure (CHF), corresponding to an $\mathrm{NNH}$ of 8 and 250 respectively. A phase IV clinical study of MX to assess its long-term safety and tolerability reported a 2\% CHF occurrence in January 2008 (Rivera 2008). A registry has been established (Goodkin 2001) to evaluate MX long-term cardiotoxicity.

From a practical point of view, cardiotoxicity can be reduced by 
performing an electrocardiogram and echocardiography (echocardiogram, multi-gated cardiac scan (MUGA), MRI etc.) in all patients before initiation of therapy, and by performing an echocardiography every year during therapy and yearly after cessation of therapy (FDA 1999; FDA 2012; FDA 2012b). However, the recent report of the occurrence of delayed cardiotoxicity 24, 39 and 80 months after the last dose in three MS patients treated with a cumulative dose of $144 \mathrm{mg} / \mathrm{m}^{2}$ of MX underpins the need to extend the long-term surveillance of MX cardiotoxicity (Goffette 2005). Moreover, an echocardiography should be performed whenever patients develop symptoms of CHF. Treatment should never be started if the baseline LVEF is below $50 \%$ and should be stopped if the LVEF decreases by more than $10 \%$ from the baseline value or to below $50 \%$ during therapy. The total cumulative dosage of MX should not be higher than $100 \mathrm{mg} / \mathrm{m}^{2}$. It seems important to also reduce the rate of infusion over 30 minutes in order to decrease peak drug levels, which could be associated with a higher risk of cardiotoxicity (Gonsette 2003). A study (Bernitsas 2006) tested the potential reduction of MX-related cardiotoxicity by the concomitant administration of dexrazoxane (DRX). This drug protects the heart by chelating iron from complexes of iron and anthracyclines and reducing free radical formation (Mikol 2001; Weiss 1999). It could be administered to patients at the beginning of MX therapy. MS patients treated with $(n=28)$ or without DRX in conjunction with MX had significant LEVF reduction at one year, however the reduction was proportionally different $(-3.8 \%$ compared to $-8.6 \%, \mathrm{P}<0.001$ ) (Bernitsas 2006).

We are aware of the development of a new analogue of MX, named BBR2778 or pixantrone (PIX), which belongs to a novel class of anthracene-9,10 diones characterized by the introduction of a nitrogen functionality in the nucleus and by the lack of two hydroxy groups. This could be an effective treatment for MS and not cardiotoxic (Krapcho 1994). According to experimental studies on EAE animal models, PIX was found to reduce the severity of the disease and, unlike MX, not to be cardiotoxic (Cavaletti 2004). Moreover, the weak cardiotoxicity of PIX has been confirmed in three phase II trials in PIX-treated patients affected with different tumours. We do not have more recent information on this drug.

\section{Overall completeness and applicability of evidence}

Despite the several sources of potential heterogeneity across the included trials, in terms of outcome measures definition (disability progression), inclusion criteria, and treatment dosage and regimen, they support and confirm the short-term efficacy and safety of the drug.

\section{Quality of the evidence}

Three trials involving 221 participants provided moderate evidence on the efficacy and short-term safety of the drug but no information on longer follow-up. Overall, their methodological quality was considered to be good with regard to the most common and relevant biases, even if type of issues found was heterogeneous

\section{Potential biases in the review process}

A careful and comprehensive search was performed to limit bias in the review process, which was not language restricted and was expanded to other sources, such as contacts with authors of the primary articles. The evaluation of eligibility of studies for inclusion in this review and the extraction of data were performed independently in order to minimise the additional potential biases to those already reported in the risk of bias table (Characteristics of included studies). Any disagreement was resolved by discussion between authors. Only three randomised, double-blinded controlled trials comparing MX administration versus placebo have been retrieved from the literature.

\section{Agreements and disagreements with other studies or reviews}

Our review is in substantial agreement with the more recent version of the report of the Therapeutics and Technology Assessment Subcommittee of the American Academy of Neurology (Marriott 2010), which supports the efficacy of MX but also strengthens the long-term risk of cardiotoxicity and TRAL related to this drug, found in long-term observational studies.

\section{AUTHORS, CONCLUSIONS}

\section{Implications for practice}

We found a moderate effect of MX treatment in reducing disability progression and the frequency of exacerbations in patients affected by worsening RR, PR and SPMS in the short-term follow-up (two years). Information on the frequency and severity of side effects and adverse events is limited to a follow-up period of two years, while the efficacy and safety of MX in longer follow-up is described in the framework of a few observational studies.

Given the partial efficacy of MX and the increased reports in the literature of cardiotoxicity ( $-12 \%$ of risk of systolic disfunction) and therapy-related leukemias events $(0.8 \%)$ in MX-treated patients, MX should be limited to treating patients with worsening RR and SP MS with evidence of persistent inflammatory activity, after a careful assessment of the individual patients' risk and benefit profiles, which should also consider the availability of alternative 
therapies with less severe adverse events. Moreover, MX-treated patients need to be followed-up after the end of treatment to control the risk of these serious adverse events. Also, the selection of which drug to switch to needs to be considered carefully in light of the risk of tumour or progressive multifocal leucoencephalopathy (PML) occurrence.

Given the evidence of a dose-effect relationship for adverse events, a more favourable risk-benefit profile of MX might be considered when the drug is used for a short-term induction treatment followed by a maintenance immunomodulating treatment.

\section{Implications for research}

There is a need to provide efficacy and safety data (namely, registries to carefully follow the risk of cardiotoxicity and TRAL among MX-treated patients) for longer follow-up periods than those reported in clinical trials. Other questions still open are as follows.

1) What is the optimal treatment regimen in terms of total dosage, frequency of administration and treatment duration?

2) Which type of MS patient benefits most from the therapy?
3) Should patients receive additional treatment during the MX cycle, namely a combined therapeutical strategy?

4) What is the efficacy of the drug considering paraclinical measures of disease burden and evolution?

A large multicentre phase III trial of mitoxantrone in SP and worsening RRMS is highly warranted to replicate data obtained in the largest MIMS study (Hartung 2002) with similar dosage and frequency of administration.

Moreover, a special effort should be made to implement potential cardioprotective agents in order to reduce the risk of MX-related cardiotoxicity and to allow the duration of MX treatment to be extended. A phase I trial with PIX and one with DRX on rapidly progressing MS are highly warranted (Gonsette 2004).

\section{ACK NOW LEDGEMENTS}

We wish to thank Dr Graziella Filippini for her useful comments during the preparation of the manuscript and the authors of the trials for providing us with missing or unpublished data.

\section{REFERE N C E S}

\section{References to studies included in this review}

Edan 1997 \{published data only\}

* Edan G, Miller D, Clanet M, Confavreux C, Lyon-Caen $\mathrm{O}$, Lubetzki $\mathrm{C}$, et al.Therapeutic effect of mitoxantrone combined with methylprednisolone in multiple sclerosis: a randomised multicentre study of active disease using MRI and clinical criteria. Journal of Neurology, Neurosurgery, and Psychiatry 1997;62(2):112-8.

Hartung 2002 \{published data only\}

* Hartung HP, Gonsette R, Konig N, Kwiecinski H, Guseo A, Morrissey SP, et al.Mitoxantrone in progressive multiple sclerosis: a placebo-controlled, double-blind, randomised, multicentre trial. Lancet 2002;360(9350):2018-25.

Hartung HP, Gonsette R, the MIMSSG. Mitoxantrone in progressive multiple sclerosis: a placebo-controlled, randomized, observer-blind phase III trial: clinical results and three-year follow-up. Neurology 1999;52 Suppl 2:A290 (S45.005).

Krapf H, Morrissey SP, Zenker O, Zwingers T, Gonsette R, Hartung HP, et al.Mitoxantrone in progressive multiple sclerosis: MRI results of the european phase III trial. Neurology 1999;52 Suppl 2:A495 (P06.044).

Krapf H, Morrissey SP, Zenker O, Zwingers T, Gonsette R, Hartung HP, Group MIMS Study. Effect of mitoxantrone on MRI in progressive MS: results of the MIMS trial.
Neurology 2005;65(5):690-5.

Nadeau SE. Effect of mitoxantrone on MRI in progressive MS: results of the MIMS trial. Neurology 2006;66:1457-8.

Millefiorini 1997 \{published data only\}

Bastianello S, Pozzilli C, D’Andrea F, Millefiorini E, Trojano $\mathrm{M}$, Morino S, et al.A controlled trial of mitoxantrone in multiple sclerosis: Serial MRI evaluation at one year. The Canadian Journal of Neurological Sciences 1994;21(3): 266-70.

* Millefiorini E, Gasperini C, Pozzilli C, D'Andrea F, Bastianello S, Trojano M, et al.Randomized placebocontrolled trial of mitoxantrone in relapsing-remitting multiple sclerosis: 24-month clinical and MRI outcome. Journal of Neurology 1997;244:153-9. [MEDLINE: 9050955]

\section{References to studies excluded from this review}

\section{Capra 1993 \{published data only\}}

Capra R, Marciano N. Mitoxantrone therapy of secondary progressive multiple sclerosis: pilot study. Neurology 1993; 43(4 Suppl 2):A281.

Edan 2001 \{published data only\}

Edan G, Le Page E, Taurin G, Le Duff F, Kerdoncuff V, De Marco O, et al.Safety profile of mitoxantrone in a cohort of 293 multiple sclerosis patients. Neurology 2001;56 Suppl 3:A149. 
Edan 2011 \{published data only\}

Edan G, Comi G, Le Page E, Leray E, Rocca MA, Filippi $\mathrm{M}$. Mitoxantrone prior to interferon beta- $1 \mathrm{~b}$ in aggressive relapsing multiple sclerosis: a 3-year randomised trial. Journal of Neurology, Neurosurgery, and Psychiatry 2011;82: 1344-50.

Gonsette 1990 \{published data only\}

Gonsette RE, Demonty L. Immunosuppression with mitoxantrone in multiple sclerosis: a pilot study for 2 years in 22 patients. Neurology 1990;40 Suppl 1:537.

Goodkin 2001 \{published data only\}

Goodkin DE. Registry to evaluate Novantrone effects in worsening MS (the RENEW study): a work in progress. Multiple Sclerosis 2001;7 Suppl 1:129.

Hamzehloo 2007 \{published data only\}

Hamzehloo A, Etemadifar M. Mitoxantrone reduced disability in Iranian patients with multiple sclerosis. Archives of Iranian Medicine 2007;10(1):59-64.

Kappos 1990 \{published data only\} Kappos L, Gold R, Kunstler E, Rohrbach E, Heun R, Stadt $\mathrm{D}$, et al.Mitoxantrone in the treatment of rapidly progressive MS: a pilot study with serial gadolinium (Gd)enhanced MRI. Neurology 1990;40 Suppl 1:261.

Kornhuber 1992 \{published data only\} Mauch E, Kornhuber HH, Krapf H, Fetzer U, Laufen $\mathrm{H}$. Treatment of multiple sclerosis with mitoxantrone. European Archives of Psychiatry and Clinical Neuroscience 1992;242:96-102.

Krapf 1995 \{published data only\} Krapf H, Mauch E, Fetzer U, Laufen H, Kornhuber HH. Serial gadolinium-enhanced magnetic resonance imaging in patients with multiple sclerosis treated with mitoxantrone. Neuroradiology 1995;37(2):113-9.

Mauch 1999 \{published data only\}

Mauch E, et al.Mitoxantrone in the treatment of patients with multiple sclerosis (MS): a large single-center experience. Multiple Sclerosis 1999;5 Suppl 1:94.

Noseworthy 1993 \{published data only\}

Noseworthy JH, Hopkins MB, Vandervoort MK, Karlik SJ, Lee DH, Penman M, et al.An open-trial evaluation of mitoxantrone in the treatment of progressive MS. Neurology 1993;43(7):1401-6.

Rees 1998 \{published data only\}

Reess J, et al.Results of an open study with 75 MS patients treated with mitoxantrone. 14th Congress of the European Committee for treatment and research in multiple sclerosis - Multiple Sclerosis. 1998, issue 4:382.

Van de Wyngaert 2001 \{published data only\}

Van de Wyngaert FA, Beguin C, D'Hooghe MB, Dooms G, Lissoir F, Carton H, et al.A double-blind clinical trial of mitoxantrone versus methylprednisolone in relapsing, secondary progressive multiple sclerosis. Acta Neurologica Belgica 2001;101(4):210-6.

\section{Additional references}

\section{Avasarala 2003}

Avasarala JR, Cross AH, Clifford DB, Singer BA, Siegel BA, Abbey EE. Rapid onset mitoxantrone-induced cardiotoxicity in secondary progressive multiple sclerosis. Multiple Sclerosis 2003;9(1):59-62.

Benjamin 1985

Benjamin RS, Chawla SP, Ewer MS. Evaluation of mitoxantrone cardiac toxicity by nuclear angiography and endomyocardial biopsy: an update. Investigational New Drugs 1985;3:117-21.

Bernitsas 2006

Bernitsas E, Wei W, Mikol DD. Suppression of mitoxantrone cardiotoxicity in multiple sclerosis patients by dexrazoxane. Annals of Neurology 2006;59(1):206-9.

Brassat 2002

Brassat D, Recher C, Waubant E, Le Page E, Rigal-Huguet F, Laurent G, et al.Therapy-related acute myeloblastic leukemia after mitoxantrone treatment in a patient with MS. Neurology 2002;59(6):954-5.

Cattaneo 2003

Cattaneo C, Almici C, Borlenghi E, Motta M, Rossi G. A case of acute promyelocytic leukaemia following mitoxantrone treatment of multiple sclerosis. Leukemia 2003;17(5):985-6.

Cavaletti 2004

Cavaletti G, Cavaletti E, Crippa L, Di Luccio E, Oggioni N, Lolli F, et al.Pixantrone (BBR2778) reduces the severity of experimental allergic encephalomyelitis. Journal of Neuroimmunology 2004;151:55-65.

Compston 1998

Compston AMW, Lassmann H, Ebers G, Wekerle H. McAlpine's Multiple Sclerosis. Churchill Livingstone, New York, 1998.

De Castro 1995

De Castro S, Cartoni D, Millefiorini E, Funaro S, Gasperini C, Morino S, et al.Noninvasive assessment of mitoxantrone cardiotoxicity in relapsing remitting multiple sclerosis. Journal of Clinical Pharmacology 1995;35(6):627-32.

Debouverie 2004

Debouverie M, Vandenberghe N, Morrissey SP, Anxionnat R, Vespignani H, Edan G, et al.Predictive parameters of mitoxantrone effectiveness in the treatment of multiple sclerosis. Multiple Sclerosis 2004;10:407-12.

Delisse 2004

Delisse B, De Seze J, Mackowiak A, N’ Kendjuo JB, Verier A, Derepeer O, et al.Therapy related acute myeloblastic leukaemia after mitoxantrone treatment in a patient with multiple sclerosis. Multiple Sclerosis 2004;10:92.

DerSimonian 1986

DerSimonian R, Laird N. Meta-analysis in clinical trials. Controlled Clinical Trials 1986;7(3):177-88.

Durr 1983

Durr FE, Wallace RE, Citarella RV. Molecular and biochemical pharmacology of mitoxantrone. Cancer Treatment Reviews 1983;10 Suppl B:3-11. 


\section{Edan 2001}

Edan G, Brochet B, Clanet M, et al.Safety profile of mitoxantrone in a cohort of 800 multiple sclerosis patients. Multiple Sclerosis 2001;7:S14.

\section{Ehninger 1986}

Ehninger G, Proksch B, Heinzel G, Woodward DL. Clinical pharmacology of mitoxantrone. Cancer Treatment Reports 1986;70(12):1373-8.

\section{FDA 1999}

U.S. Food, Drug Administration. FDA safety review. NDA 21-120, Novantrone. http://www.fda.gov/ohrms/dockets/ ac/00/backgrd/3582b1c.pdf (accessed February 2013).

\section{FDA 2012}

U.S. Food, Drug Administration. FDA Medication Guide. http://www.fda.gov/downloads/Drugs/DrugSafety/ UCM297876.pdf (accessed February 2013).

\section{FDA 2012b}

U.S. Food, Drug Administration. FDA Medication Guide. http://www.accessdata.fda.gov/drugsatfda docs/label/2012/ 019297s035lbl.pdf (accessed February 2013).

\section{Felix 1998}

Felix CA. Secondary leukemias induced by topoisomerasetargeted drugs. Biochimica et Biophysica Acta 1998;1400(13):233-55.

\section{Fidler 1985}

Fidler JM, Smith F, Gibbons J. Mitoxantrone inhibits helper function and enhances suppressor activity. Agents and Actions 1985;16:607-8.

\section{Fidler 1986a}

Fidler JM, DeJoy SQ, Gibbons JJ, Jr. Selective immunomodulation by the antineoplastic agent mitoxantrone. I. Suppression of B lymphocyte function. Journal of Immunology 1986;137(2):727-32.

Fidler 1986b

Fidler JM, DeJoy SQ, Smith FR 3rd, Gibbons JJ Jr. Selective immunomodulation by the antineoplastic agent mitoxantrone. II. Nonspecific adherent suppressor cells derived from mitoxantrone- treated mice. Journal of Immunology 1986;136(8):2747-54.

\section{Filippi 1998}

Filippi M, Horsfield MA, Ader HJ, Barkhof F, Bruzzi P, Evans A, et al.Guidelines for using quantitative measures of brain magnetic resonance imaging abnormalities in monitoring the treatment of multiple sclerosis. Annals of Neurology 1998;43(4):499-506.

Filippi 2001

Filippi M. Linking structural, metabolic and functional changes in multiple sclerosis. European Journal of Neurology 2001;8:291-7.

\section{Filippini 2003}

Filippini G, Munari L, Incorvaia B, Ebers GC, Polman C, D'Amico R, et al.Interferons in relapsing remitting multiple sclerosis: a systematic review. Lancet 2003;361:545-52.

\section{Ghalie 2002a}

Ghalie RG, Mauch E, Edan G, Hartung HP, Gonsette RE, Eisenmann $S$, et al.A study of therapy-related acute leukaemia after mitoxantrone therapy for multiple sclerosis. Multiple Sclerosis 2002;8(5):441-5.

\section{Ghalie 2002b}

Ghalie RG, Edan G, Laurent M, Mauch E, Eisenman S, Hartung HP, et al.Cardiac adverse effects associated with mitoxantrone (Novantrone) therapy in patients with MS Neurology 2002;59(6):909-13.

\section{Goffette 2005}

Goffette S, Van Pesch V, Vanoverschelde JL, Morandini E, Sindic CJ. Severe delayed heart failure in three multiple sclerosis patients previously treated with mitoxantrone. Journal of Neurology 2005;252(10):1217-22.

\section{Gonsette 2003}

Gonsette RE. Mitoxantrone in progressive multiple sclerosis: when and how to treat?. Journal of the Neurological Sciences 2003;206(2):203-8.

\section{Gonsette 2004}

Gonsette RE. Pixantrone (BBR2778): a new immunosuppressant in multiple sclerosis with a low cardiotoxicity. Journal of the Neurological Sciences 2004;223: 81-6.

\section{Goodkin 1992}

Goodkin DE, Cookfair D, Wende K, Bourdette D, Pullicino P, Scherokman B, et al.Inter- and intra-rater scoring agreement using grades 1.0 to 3.5 of the Kurtzke Expanded Disability Status Scale (EDSS). Neurology 1992; 42:859-63.

\section{Goodkin 2003}

Goodkin DE. Therapy-related leukaemia in mitoxantrone treated patients. Multiple Sclerosis 2003;9:426.

\section{Heesen 2003}

Heesen C, Bruegmann M, Gbdamosi J, Koch E, Monch A, Buhmann C. Therapy-related acute myelogenous leukaemia $(\mathrm{t}-\mathrm{AML})$ in a patient with multiple sclerosis treated with mitoxantrone. Multiple Sclerosis 2003;9(2):213-4.

\section{Higgins 2011}

Higgins JPT, Green S (editors). Cochrane Handbook for Systematic Reviews of Interventions Version 5.1.0 [updated March 2011]. The Cochrane Collaboration 2011:Available from www.cochrane-handbook.org.

\section{Kieseier 2011}

Kieseier BC, Stüve O. A critical appraisal of treatment decisions in multiple sclerosis-old versus new. Nature Reviews. Neurology 2011;7(5):255-62.

\section{Krapcho 1994}

Krapcho AP, Petry ME, Getahun Z, Landi JJ Jr, Stallman J, Polsenberg JF, et al.6,9-bis[ (aminoalkyl)amino]benzo[g]isoquinoline-5,10-diones. A novel class of chromophore-modified antitumor anthracene9,10-diones: synthesis and antitumor evaluations. Journal of Medicinal Chemistry 1994;37(6):828-37. 


\section{Kurtzke 1983}

Kurtzke JF. Rating neurologic impairment in multiple sclerosis: an expanded disability status scale (EDSS). Neurology 1983;33(11):1444-52.

\section{La Mantia 2010}

La Mantia L, Munari LM, Lovati R. Glatiramer acetate for multiple sclerosis. Cochrane Database of Systematic Reviews 2010, Issue 5. [DOI: 10.1002/14651858.CD004678]

\section{Levine 1986}

Levine S, Gherson J. Morphologic effects of mitoxantrone and a related anthracenedione on lymphoid tissues. International Journal of Immunopharmacology 1986;8: 999-1007.

\section{Lublin 1987}

Lublin FD, Lavasa M, Viti C, Knobler RL. Suppression of acute and relapsing experimental allergic encephalomyelitis with mitoxantrone. Clinical Immunology and Immunopathology 1987;45(1):122-8.

\section{Lublin 1996}

Lublin FD, Reingold SC. Defining the clinical course of multiple sclerosis: results of an international survey. National Multiple Sclerosis Society (USA) Advisory Committee on Clinical Trials of New Agents in Multiple Sclerosis. Neurology 1996;46(4):907-11.

\section{Marriott 2010}

Marriott JJ, Miyasaki JM, Gronseth G, O'Connor PW. Evidence Report: The efficacy and safety of mitoxantrone (Novantrone) in the treatment of multiple sclerosis: Report of the Therapeutics and Technology Assessment Subcommittee of the American Academy of Neurology. Neurology 2010;74(18):1463-70.

\section{Martinelli 2011}

Martinelli V, Cocco E, Capra R, Salemi G, Gallo P, Capobianco $\mathrm{M}$, et al.Acute myeloid leukemia in Italian patients with multiple sclerosis treated with mitoxantrone. Neurology 2011;77(21):1887-95.

\section{McDonald 2001}

McDonald WI, Compston A, Edan G, Goodkin D, Hartung HP, Lublin FD, et al.Recommended diagnostic criteria for MS: guidelines from the International Panel on the diagnosis of multiple sclerosis. Annals of Neurology 2001;50:121-7.

\section{Mikol 2001}

Mikol DDBE. Novantrone plus dexrazoxane therapy in multiple sclerosis patients: a safety and tolerability pilot study. Multiple Sclerosis 2001;7 Suppl 1:14.

\section{Miller 1991}

Miller DH, Barkhof F, Berry I, Kappos L, Scotti G, Thompson AJ. Magnetic resonance imaging in monitoring the treatment of multiple sclerosis: concerted action guidelines. Journal of Neurology, Neurosurgery, and Psychiatry 1991;54(8):683-8.

\section{Mistry 2005}

Mistry AR, Felix CA, Whitmarsh RJ, Mason A, Reiter A, Cassinat $\mathrm{B}$, et al.DNA topoisomerase II in therapy-related acute promyelocytic leukemia. New England Journal of

Medicine 2005;352(15):1529-38.

\section{Mustafa 1993}

Mustafa M, Diener P, Sun JB, Link H, Olsson T. Immunopharmacologic modulation of experimental allergic encephalomyelitis: low-dose cyclosporin-A treatment causes disease relapse and increased systemic $\mathrm{T}$ and $\mathrm{B}$ cell-mediated myelin-directed autoimmunity. Scandinavian Journal of Immunology 1993;38(6):499-507.

\section{Olindo 2002}

Olindo S, Guillon B, Helias J, Phillibert B, Magne C, Feve $J R$. Decrease in heart ventricular ejection fraction during multiple sclerosis. European Journal of Neurology 2002;9(3): 287-91.

\section{Polman 2005}

Polman CH, Reingold SC, Edan G, Filippi M, Hartung HP, Kappos L, et al.Diagnostic criteria for multiple sclerosis: 2005 revisions to the "McDonald Criteria". Annals of Neurology 2005;58(6):840-6.

\section{Polman 2011}

Polman CH, Reingold SC, Banwell B, Clanet M, Cohen JA, Filippi M, et al.Diagnostic criteria for multiple sclerosis: 2010 revisions to the McDonald criteria. Annals of Neurology 2011;69(2):292-302.

\section{Poser 1983}

Poser CM, Paty DW, Scheinberg L, McDonald WI, Davis FA, Ebers GC, et al.New diagnostic criteria for multiple sclerosis: guidelines for research protocols. Annals of Neurology 1983;13(3):227-31.

\section{Quesnel 1993}

Quesnel B, Kantarjian H, Pedersen-Bjergaard J, Brault P, Estey E, Harousseau JL, et al.Therapy-related acute myeloid leukemia with $\mathrm{t}(8 ; 21)$, inv (16) and $\mathrm{t}(8 ; 16)$ : A report on 25 cases and review of the literature. Journal of Clinical Oncology 1993;11:2370-9.

\section{Radu 2002}

Radu TD, Marc D, Herve V. Acute myeloid leukaemia (AML) induced by mitoxantrone. Multiple Sclerosis 2002;8: 342 (S127).

\section{Ramey 1992}

Ramey DR, Reynauld JP, Fries JF. The health assessment questionnaire. Arthritis Care Research 1992;5:119-29.

\section{Review Manager 2013}

The Nordic Cochrane Centre, The Cochrane Collaboration. Review Manager (RevMan). 5.2. Copenhagen: The Nordic Cochrane Centre, The Cochrane Collaboration, 2013.

\section{Rice 2001}

Rice GP, Incorvaia B, Munari L, Ebers G, Polman C, D'Amico R, et al.Interferon in relapsing-remitting multiple sclerosis. Cochrane Database of Systematic Reviews 2001, Issue 4. [DOI: 10.1002/14651858.CD002002]

\section{Rivera 2008}

Rivera V, Al-Sabbagh A, Bennett R, et al.RENEW study update XVIII: Ongoing evaluation of the safety and 
tolerability of mitoxantrone in worsening multiple sclerosis. Multiple Sclerosis 2008;14 Suppl 1:175.

\section{Sibley 1996}

Sibley W. A guide to treatments. 4th edition. New York: Demos Vermande, 1996.

\section{Smith 1983}

Smith IE. Mitoxantrone (Novantrone): a review of experimental and early clinical studies. Cancer Treatment Reviews 1983;10:103-15.

\section{Stewart 1986}

Stewart DJ, Green RM, Mikhael NZ, Montpetit V, Thibault M, Marcoun JA. Human autopsy tissue concentrations of mitoxantrone. Cancer Treatment Reports 1986;70:1255-61.

\section{Thompson 2010}

Thompson AJ, Toosy AT, Ciccarelli O. Pharmacological management of symptoms in multiple sclerosis: current approaches and future directions. Lancet Neurology 2010;9 (12):1182-99.

\section{Vicari 1998}

Vicari AM, Ciceri F, Folli F, Lanzi R, Colombo B, Comi G, et al.Acute promyelocytic leukemia following mitoxantrone as single agent for the treatment of multiple sclerosis. Leukemia 1998;12(3):441-2.

\section{Voltz 2004}

Voltz R, Starck M, Zingler V, Strupp M, Kolb HJ. Mitoxantrone therapy in multiple sclerosis and acute leukaemia: a case report out of 644 treated patients. Multiple Sclerosis 2004;10:472-4.

\section{Watson 1991}

Watson CM, Davison AN, Baker D, O’Neill JK, Turk JL. Suppression of demyelination by mitoxantrone. International Journal of Immunopharmacology 1991;13(7): 923-30.

\section{Weinshenker 1989}

Weinshenker BG, Bass B, Rice GP, Noseworthy J, Carriere W, Baskerville J, et al.The natural history of multiple sclerosis: a geographically based study. I. Clinical course and disability. Brain 1989;112 Pt 1:133-46.

\section{Weiss 1999}

Weiss G, Loyevsky M, Gordeuk VR. Dexrazoxane (ICRF187). General Pharmacology 1999;32(1):155-8.

\section{Yusuf 1985}

Yusuf SPR, Lewis J, Collins R, Sleight P. Beta-blockade during and after myocardial infarction: an overview of the randomized trials. Progress in Cardiovascular Diseases 1985; 27(5):335-71.

\section{References to other published versions of this review}

\section{Martinelli Boneschi 2013}

Martinelli Boneschi F, Vacchi L, Rovaris M, Capra R, Comi G. Mitoxantrone for multiple sclerosis. Cochrane Database of Systematic Reviews 2013, Issue 5. [DOI: 10.1002/ 14651858.CD002127.pub3]

* Indicates the major publication for the study 


\section{CHARACTERISTICS OF STUDIES}

\section{Characteristics of included studies [ordered by study ID]}

\section{Edan 1997}

Rethods
Central randomisation.
Intention to treat used, even if not specified in the paper.
Double blinded: but in discussion it is specified that blinding of patients is difficult for
MX side effects and blinding of the physicians is difficult for the decrease in white cell
count.
Treatment period: 6 months.
No follow-up.
Withdrawn criteria: not pre-specified.
Withdrawals: 5 "due to pronounced clinical worsening “ (all in MP group).
Lost to follow-up: no follow-up.

Participants

42 patients: $21 \mathrm{MX}+$ MetylP; 21 MetylP.

6 Centres.

Sex: both.

Included: CDMS with a RR (at least 2 exacerbations with sequelae within the previous 12 months) or SP course (progression of 2 points on EDSS scale within the previous 12 months); disease duration < 10 years; age between 18 and 65 years; EDSS $\leq 6.0$; at least $1 \mathrm{MRI}$ enhancing lesion during the baseline period (defined as the period between 2 months before the baseline visit and the baseline visit, during which all the patients received $1 \mathrm{~g}$ MetylP once a month).

Excluded: coexistence of other severe illnesses; pregnancy; immunosuppressant drugs use 3 months before entry; corticotropin or corticosteroids use 1 month before entry.

Baseline characteristics:

Sex: MX+MetylP 71,4\% female; MetylP 52,3 \% female.

Mean Age (SD): MX+MetylP 31,4 years $(8,3)$; MetylP 32,2 years $(8,1)$.

Mean EDSS (SD): MX+MetylP 4.5 (1.6), MetylP 4.6 (1.7).

Mean disease duration (SD): MX+MetylP 6,9 years (3,6), MetylP 5,7 years (4).

Age at onset of MS (SD): MX+MetylP 25,1 (7); MetylP 26,6 (6,5).

Number of relapses 1 year before the inclusion (SD): MX+MetylP 3,1 $(1,8)$; MetylP 2, $4(1,7)$.

Course of disease: MX+MetylP (80,9\% RR; 19,1\% SP); MetylP (71,4\% RR; 28,6\% SP)

Interventions

Rx: 20 mg MX + 1 g. MetylP i.v.

Placebo: 1 g. MetylP i.v.

(Between Month -2 and baseline: MetylP 1 g. i.v. for either groups).

Administration: once a month.

Total dosage: MX $120 \mathrm{mg}$ over 6 months.

Outcomes

Primary outcomes:

(1) Proportion of patients who develop new T1 enhancing lesions on serial gadolinium MRI scans during trial.

Secondary outcomes:

(1) Mean number of new enhanced lesions per month per patient; (2) Mean number of 
new T2 lesions between baseline and end of trial; (3) Mean EDSS difference between baseline and end of trial; (4) Mean number of exacerbations between baseline and end of trial

Notes

Definitions: Progression of disability: Confirmed increase of 1.0 EDSS point if baseline EDSS $<=5,5$, or of a 0.5 EDSS point if baseline EDSS $>=6.0$, between month 0 and the end of the study (measured for two months running at the end of the study). Relapse: occurrence of symptoms of neurological disfunction lasting more than 48 hours and preceded by stability or improvement for at least 30 days

\section{Risk of bias}

\begin{tabular}{|c|c|c|}
\hline Bias & Authors' judgement & Support for judgement \\
\hline $\begin{array}{l}\text { Random sequence generation (selection } \\
\text { bias) }\end{array}$ & Unclear risk & Not reported. \\
\hline Allocation concealment (selection bias) & Low risk & $\begin{array}{l}\text { "The allocation of the treatment at month } \\
0 \text { was done after inclusion by a central ran- } \\
\text { domisation service by fax." Page } 113\end{array}$ \\
\hline
\end{tabular}

Blinding (performance bias and detection High risk bias)

For investigator e patients
"In the present study, although the allocation of treatment was performed using an unbiased randomisation service, neither the patients nor the clinical investigators were blinded during the study. Blinding of patients was not possible in this trial, as obvious side effects of mitoxantrone were experienced in almost all cases. Blinding of the physician was made difficult by the fall in white cell count that always accompanies mitoxantrone treatment. Blind clinical observers might have been appointed, but this could not be done for economic reasons. The clinical efficacy suggested in this study must therefore be regarded with caution as it was acquired unblinded." (Page 116) Only the two MRI observers were blinded to patients' clinical status

5 withdrawals "due to pronounced clinical worsening" (all in the methylprednisolone group) were not included in the 6 months follow-up analysis. Bias is toward a reduced efficacy of the drug, on the reduction of the disability progression since all excluded patients in the control group worsened during the study 
Edan 1997 (Continued)

\begin{tabular}{|l|l|l}
\hline Selective reporting (reporting bias) & Low risk & $\begin{array}{l}\text { Protocol not available. Outcomes were re- } \\
\text { ported completely, even if the total number } \\
\text { of relapses in the two arms was reported, } \\
\text { but not the distribution in patients. More- } \\
\text { over, the two arms were not matched for } \\
\text { baseline number of enhancing lesions }\end{array}$ \\
\hline Other bias & High risk & $\begin{array}{l}\text { Sustained disability progression confirmed } \\
\text { every 2 months. } \\
\text { Possibility that part of the benefit reported } \\
\text { in the mitoxantrone group came from } \\
\text { the addition of methylprednisolone to the } \\
\text { treatment regimen } \\
\text { Notes: It's unclear if this study was spon- } \\
\text { sored. }\end{array}$ \\
\hline
\end{tabular}

Hartung 2002

\begin{tabular}{|c|c|}
\hline Methods & $\begin{array}{l}\text { Randomised controlled trial. } \\
\text { Central computer randomisation. } \\
\text { Intention to treat. }\end{array}$ \\
\hline Participants & 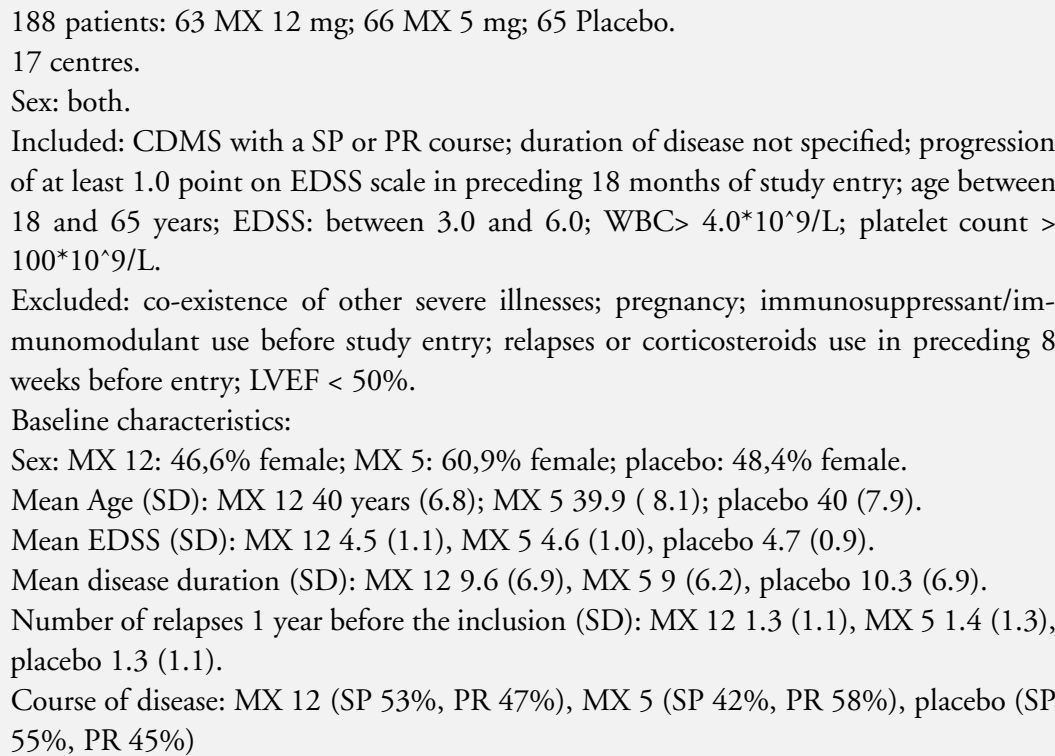 \\
\hline
\end{tabular}

Interventions

Rx: MX 12: $12 \mathrm{mg} / \mathrm{m}^{2}$ body surface i.v. + ondansentron $8 \mathrm{mg}$ per os.

Rx MX 5: $5 \mathrm{mg} / \mathrm{m}^{2}$ body surface i.v. + ondansentron $8 \mathrm{mg}$ per os.

Placebo: placebo solution $(15 \mathrm{mg})+3 \mathrm{mg}$ methylene blue i.v.

+ ondansentron $16 \mathrm{mg}$ per os.

Administration every 3 months over 24 months. Total dosage: MX 12, 8 dosages over

24 months (total: $96 \mathrm{mg} / \mathrm{m}^{2}$ body surface). MX 5: 8 dosages over 24 months (total: 40 
Hartung 2002 (Continued)

$\mathrm{mg} / \mathrm{m}^{2}$ body surface).

The Rx MX 5: $5 \mathrm{mg} / \mathrm{m}^{2}$ body surface i.v. + ondansentron $8 \mathrm{mg}$ per os arm was excluded from the analyses

Primary outcomes:
1) EDSS difference between final and baseline.
2) Ambulation index (AI) difference between final and baseline.
3) Number of treated relapses.
4) Time to first treated relapse.
5) Proportion of patients with confirmed EDSS progression.
Secondary outcomes:
6) Proportion of patients with deterioration of at least 1.0 EDSS point.
7) Proportion of patients with such EDSS deterioration confirmed after 3 and 6 months.
8) Time to first sustained EDSS deterioration
9) Time to first relapse.
10) Number and annualised rate of relapses.
11) Proportion of patients with no relapses.
12) Number of days of hospitalisation.
13) Use of wheelchair assistance.
14) Quality of life assessed by Stanford Health questionnaire.
15) Number and volume of gadolinium-enhancing lesions.
16) Number and volume of T-1 lesions.
17) Number and volume of T-2 scans.

Notes

Definitions:

Progression of disability: 6-months confirmed increase of at least 1.0 EDSS point.

Relapse: occurrence of new symptoms lasting for more than 48 hours with a change in functional systems of more than 2 points or deterioration of at least 1 point in either piramidal, brainstem, cerebellar or visual FS

Risk of bias

Bias

Authors' judgement

Support for judgement

Random sequence generation (selection Low risk bias)

"Randomisation was done by means of a computer-generated schedule prepared for each site with a block size of three, without stratification.” Page 2019

Allocation concealment (selection bias) Unclear risk Not reported.

Blinding (performance bias and detection Low risk bias)

For investigator e patients

EDSS assessor was unaware. A separate treating physician was aware of treatment assignment. Lesion load was estimated by means of a scoring system by two experienced readers, masked to treatment assignment (Page 2020).

"This physician was allowed to speak to patients only as necessary to carry out 
Hartung 2002 (Continued)

\begin{tabular}{|c|c|c|}
\hline & & $\begin{array}{l}\text { the neurological tests. Before patients were } \\
\text { enrolled, assessing physicians completed } \\
\text { a training session to standardise scoring } \\
\text { on the three tests [EDSS, ambulation in- } \\
\text { dex and standardised neurological status } \\
\text { scores]" Page } 2019\end{array}$ \\
\hline $\begin{array}{l}\text { Incomplete outcome data (attrition bias) } \\
\text { All outcomes }\end{array}$ & Low risk & $\begin{array}{l}\text { The authors state that " } 188 \text { patients were } \\
\text { included in the intention-to-treat analysis } \\
\text { of efficacy at } 24 \text { months" ( } 194 \text { at the onset) } \\
\text {. Reasons seemed similar }\end{array}$ \\
\hline Selective reporting (reporting bias) & Low risk & $\begin{array}{l}\text { Protocol not available. Outcomes were re- } \\
\text { ported completely. }\end{array}$ \\
\hline Other bias & Low risk & $\begin{array}{l}\text { Notes: Wyeth-Lederle Benelux and Ger- } \\
\text { many sponsored this trial and financially } \\
\text { supported independent statistical analysis. } \\
\text { Page } 2021\end{array}$ \\
\hline
\end{tabular}

\section{Millefiorini 1997}

Methods

Participants
Randomised controlled trial.

Central randomisation and allocation.

Intention to treat.

51 patients: 27 MX $8 \mathrm{mg}$; 24 Placebo.

8 centres.

Sex: both.

Included: CDMS or LSMS with a RR course; disease duration between 1 and 10 years; at least 2 relapses in the previous 2 years; age between 18 and 45 years; EDSS: between 2.0 and 5.0; MRI criteria not specified.

Excluded: presence of previous cardiovascular disease; pregnancy; immunosuppressant drugs use 3 months before entry; relapses or corticosteroids use in preceding 3 months before entry; $\mathrm{LVEF}<50 \%$.

Baseline characteristics:

Sex: MX 8 (62.9\% female); placebo (75\% female).

Mean Age (SD): MX 830.9 years (6.0); placebo 28.7 (6.5).

Mean EDSS (SD): MX 83.6 (0.9), placebo 3.5 (1.2).

Mean disease duration (SD): MX 85.7 years; placebo 5.0.

Number of relapses 2 years before the inclusion (SD): MX 82.8 (1.2), placebo 2.8 (1. 1).

Course of disease: MX 8, RR 100\%; placebo, RR 100\%.

Interventions
Rx: MX 8: $8 \mathrm{mg} / \mathrm{m}^{2}$ body surface i.v.

Placebo: placebo solution i.v.

Administration: every month over 12 months (total dosage: $96 \mathrm{mg} / \mathrm{m}^{2}$ body surface). 
Millefiorini 1997 (Continued)

\begin{tabular}{ll}
\hline Outcomes & $\begin{array}{l}\text { Primary outcomes: } \\
\text { (1) Proportion of patients with confirmed progression (2) Annual mean number of } \\
\text { exacerbations and percentage of exacerbation-free patients; }\end{array}$ \\
\hline (3) Change in mean EDSS from baseline to final; \\
(4) Mean number of new or enlarged T2-lesions performed at baseline, 12-month and \\
24-month
\end{tabular}

Risk of bias

Bias

Random sequence generation (selection Low risk bias)
Authors' judgement

Support for judgement

"When a patient became eligible, the investigators notified the relevant centre which validated the eligibility of the patient and assigned a randomisation code number. The subject was then randomly assigned to a recipient group that received either MTX or a placebo. Patients were randomised to MTX or placebo using a scheme stratified on age, sex and EDSS which resulted in eight different age/sex/EDSS strata. According to the study protocol, within each stratum the allocation of patients to treatment or placebo was balanced by using a block design of size eight.” Page 154

Allocation concealment (selection bias) Low risk

Blinding (performance bias and detection Low risk bias)

For investigator e patients
Central allocation and the intravenous bag and tubing were black to ensure no differences between the treatment groups. Page 154

The neurologist, who evaluated the EDSS scale, was blinded. "In order to maintain blindness, the interaction of the EDSS physicians with the patient was strictly restricted to the neurological examination. The neurologist was not allowed to talk with the patient about adverse events, or any other issue which could potentially dis- 
Millefiorini 1997 (Continued)

close the patient's treatment." Page 154

"MRI data were analysed by two blinded neuroradiologists" Page 155

BUT "It must be emphasized that while EDSS evaluation was performed by four blinded neurologists, the assessment of exacerbations was monitored by treating physicians not blinded to study treatment (see Patients and methods). The unblended assessment of exacerbations suggests a potential systematic bias concerning treatment efficacy (false positive, type 1 error) . This type of error, however, is a crucial element when the EDSS score must be assigned, while it seems to be less relevant in recording objective neurological findings such as determining that an exacerbation has taken place." Page 157

Incomplete outcome data (attrition bias) Low risk All outcomes
All randomised patients were included in the analysis.

For MRI outcome measure, 9 out of 51 patients did not complete the MRI study for the following reasons: $2 \mathrm{MX}$ and 4 placebo patients felt the drug was not working, 1 MX patient did not have good compliance with his neuroradiological centre, $1 \mathrm{MX}$ and 1 placebo patients withdrew for nonmedical reasons

Selective reporting (reporting bias) Low risk

Protocol not available. Outcomes were reported completely, even if "The lack of a total lesion volume evaluation on T2weighted images, which is the most appropriate measurement for long-term studies, and the use of different MRI imagers, which might be a significant source of variation for lesion measurements, appear to be the major limitations of the present study and might explain the apparent incongruity between clinical and MRI results.” Page 157-158

Other bias

High risk
"The incomplete recruitment generated an imbalance in term of sex." Page 155

No adequate AEs monitoring (self-reported).

Notes: It is unclear if this study was sponsored. 
CDMS: Clinically-definite multiple sclerosis

EDSS: Expanded Disability Status Scale

LSMS: Laboratory-supported multiple sclerosis

LVEF: Left ventricular ejection fraction

MetylP: Methylprednisolone

MS: Multiple sclerosis

MRI: Magnetic Resonance Imaging

MX: Mitoxantrone

PR: Progressive relapsing

RR: Relapsing-remitting

SD: Standard deviation

SP: Secondary progressive

WBC: White blood count

I.V.: Intravenous

Characteristics of excluded studies [ordered by study ID]

\begin{tabular}{|c|c|}
\hline Study & Reason for exclusion \\
\hline Capra 1993 & Open label pilot study \\
\hline Edan 2001 & Observational safety study \\
\hline Edan 2011 & RCT, absence of placebo arm \\
\hline Gonsette 1990 & Open label pilot study \\
\hline Goodkin 2001 & Observational safety study \\
\hline Hamzehloo 2007 & Observational study \\
\hline Kappos 1990 & Open label pilot study \\
\hline Kornhuber 1992 & Open label pilot study \\
\hline Krapf 1995 & Open label pilot study. Only MRI outcome \\
\hline Mauch 1999 & Observational efficacy and safety study \\
\hline Noseworthy 1993 & Open label pilot study \\
\hline Rees 1998 & Open label pilot study \\
\hline Van de Wyngaert 2001 & RCT, mitoxantrone versus methylprednisolone; absence of placebo group \\
\hline
\end{tabular}


DATA AND ANALYSES

Comparison 1. Mitoxantrone versus placebo: primary outcomes

\begin{tabular}{|c|c|c|c|c|}
\hline Outcome or subgroup title & $\begin{array}{l}\text { No. of } \\
\text { studies }\end{array}$ & $\begin{array}{c}\text { No. of } \\
\text { participants }\end{array}$ & Statistical method & Effect size \\
\hline $\begin{array}{l}1 \text { Patients with 6-month confirmed } \\
\text { disability progression at } 2 \text { years }\end{array}$ & 1 & & Odds Ratio (M-H, Fixed, 95\% CI) & Totals not selected \\
\hline 1.1 Disability progression & 1 & & Odds Ratio (M-H, Fixed, 95\% CI) & $0.0[0.0,0.0]$ \\
\hline 1.2 Worst & 1 & & Odds Ratio (M-H, Fixed, 95\% CI) & $0.0[0.0,0.0]$ \\
\hline 1.3 Best & 1 & & Odds Ratio (M-H, Fixed, 95\% CI) & $0.0[0.0,0.0]$ \\
\hline 1.4 Likely & 1 & & Odds Ratio (M-H, Fixed, 95\% CI) & $0.0[0.0,0.0]$ \\
\hline $\begin{array}{l}2 \text { Post-hoc analysis: Patients with } \\
\text { 3- or 6-month confirmed } \\
\text { disability progression }\end{array}$ & 2 & & Odds Ratio (M-H, Fixed, 95\% CI) & Subtotals only \\
\hline 2.1 At 1 year & 1 & 51 & Odds Ratio (M-H, Fixed, 95\% CI) & $0.24[0.04,1.33]$ \\
\hline 2.2 At 2 years & 2 & 179 & Odds Ratio (M-H, Fixed, 95\% CI) & $0.23[0.09,0.59]$ \\
\hline 2.3 At 2 years - Worst Scenario & 2 & 179 & Odds Ratio (M-H, Fixed, 95\% CI) & $0.36[0.16,0.83]$ \\
\hline 2.4 At 2 years - Best Scenario & 2 & 179 & Odds Ratio (M-H, Fixed, 95\% CI) & $0.21[0.08,0.55]$ \\
\hline $\begin{array}{l}2.5 \text { At } 2 \text { years - Likely } \\
\text { Scenario }\end{array}$ & 2 & 179 & Odds Ratio (M-H, Fixed, 95\% CI) & $0.34[0.15,0.78]$ \\
\hline $\begin{array}{l}3 \text { Patients who withdrew from the } \\
\text { study because of major side } \\
\text { effects of the drug }\end{array}$ & 3 & 221 & Odds Ratio (M-H, Fixed, 95\% CI) & $2.72[0.51,14.54]$ \\
\hline
\end{tabular}

Comparison 2. Mitoxantrone versus placebo: secondary outcomes

\begin{tabular}{|c|c|c|c|c|}
\hline Outcome or subgroup title & $\begin{array}{l}\text { No. of } \\
\text { studies }\end{array}$ & $\begin{array}{c}\text { No. of } \\
\text { participants }\end{array}$ & Statistical method & Effect size \\
\hline $\begin{array}{l}1 \text { Patients with no relapses at } 6 \\
\text { months/ } 1 \text { year }\end{array}$ & 2 & & Odds Ratio (M-H, Random, 95\% CI) & Totals not selected \\
\hline 1.16 months & 1 & & Odds Ratio (M-H, Random, 95\% CI) & $0.0[0.0,0.0]$ \\
\hline 1.21 year & 1 & & Odds Ratio (M-H, Random, 95\% CI) & $0.0[0.0,0.0]$ \\
\hline $\begin{array}{l}2 \text { Mean change in disability } \\
\text { (EDSS) }\end{array}$ & 2 & & Mean Difference (IV, Fixed, 95\% CI) & Subtotals only \\
\hline 2.1 At 1 year & 1 & 25 & Mean Difference (IV, Fixed, 95\% CI) & $-0.35[-0.86,0.16]$ \\
\hline 2.2 At 2 years & 2 & 175 & Mean Difference (IV, Fixed, 95\% CI) & $-0.36[-0.70,-0.02]$ \\
\hline $\begin{array}{l}3 \text { Patients with no relapses at } 2 \\
\text { years }\end{array}$ & 2 & & Odds Ratio (M-H, Fixed, 95\% CI) & Subtotals only \\
\hline 3.1 Patients with no relapses & 2 & 179 & Odds Ratio (M-H, Fixed, 95\% CI) & $2.82[1.54,5.19]$ \\
\hline 3.2 Worst Scenario & 2 & 179 & Odds Ratio (M-H, Fixed, 95\% CI) & $2.68[1.46,4.92]$ \\
\hline 3.3 Best Scenario & 2 & 179 & Odds Ratio (M-H, Fixed, 95\% CI) & $3.27[1.77,6.04]$ \\
\hline 3.4 Likely Scenario & 2 & 179 & Odds Ratio (M-H, Fixed, 95\% CI) & $3.11[1.68,5.72]$ \\
\hline 4 Annualized relapse rate & 3 & & Mean Difference (IV, Fixed, 95\% CI) & Subtotals only \\
\hline 4.1 At 6 months $/ 1$ year & 3 & 217 & Mean Difference (IV, Fixed, 95\% CI) & $-1.02[-1.69,-0.35]$ \\
\hline
\end{tabular}


4.2 At 2 years

5 Number of MRI active lesions

5.1 At 6 months/ 1 year

5.2 At 2 years

6 Number of patients with active lesions

6.1 At 6 months/ 1 year 6.2 At 2 years
132

68
Mean Difference (IV, Fixed, 95\% CI)

Mean Difference (IV, Fixed, 95\% CI)

Mean Difference (IV, Fixed, 95\% CI)

Mean Difference (IV, Fixed, 95\% CI)

Odds Ratio (M-H, Fixed, 95\% CI)
Odds Ratio (M-H, Fixed, 95\% CI) Odds Ratio (M-H, Fixed, 95\% CI)
$-0.85[-1.47,-0.23]$

Subtotals only $-0.79[-1.68,0.09]$ $0.0[0.0,0.0]$ Subtotals only

$0.24[0.10,0.57]$ $0.09[0.00,1.77]$

Comparison 3. Mitoxantrone versus placebo: adverse events

\begin{tabular}{lcclc} 
Outcome or subgroup title & $\begin{array}{c}\text { No. of } \\
\text { studies }\end{array}$ & $\begin{array}{c}\text { No. of } \\
\text { participants }\end{array}$ & Statistical method & Effect size \\
\hline 1 Amenorrea & 3 & 199 & Odds Ratio (M-H, Fixed, 95\% CI) & $15.50[4.15,57.94]$ \\
$\quad$ 1.1 Amenorrea (general) & 3 & 117 & Odds Ratio (M-H, Fixed, 95\% CI) & $22.31[4.03,123.47]$ \\
$\quad$ 1.2 Persistent Amenorrea & 2 & 82 & Odds Ratio (M-H, Fixed, 95\% CI) & $8.27[1.02,67.18]$ \\
2 Nausea/Vomiting & 3 & 219 & Odds Ratio (M-H, Fixed, 95\% CI) & $14.01[6.36,30.85]$ \\
3 Alopecia & 3 & 219 & Odds Ratio (M-H, Fixed, 95\% CI) & $4.65[2.37,9.12]$ \\
4 Urinary tract Infections & 3 & 219 & Odds Ratio (M-H, Fixed, 95\% CI) & $3.76[1.67,8.46]$ \\
5 Respiratory tract infections & 3 & 219 & Odds Ratio (M-H, Fixed, 95\% CI) & $1.34[0.72,2.50]$ \\
6 Headhache & 3 & 219 & Odds Ratio (M-H, Fixed, 95\% CI) & $1.36[0.44,4.24]$ \\
\hline
\end{tabular}

Comparison 4. Mitoxantrone versus placebo: abnormal laboratory values

\begin{tabular}{lcccc} 
Outcome or subgroup title & $\begin{array}{c}\text { No. of } \\
\text { studies }\end{array}$ & $\begin{array}{c}\text { No. of } \\
\text { participants }\end{array}$ & Statistical method & Effect size \\
\hline 1 Leucopenia & 2 & 168 & Odds Ratio (M-H, Fixed, 95\% CI) & $17.95[2.35,137.00]$ \\
2 Anemia & 2 & 168 & Odds Ratio (M-H, Fixed, 95\% CI) & $4.51[0.92,22.20]$ \\
\hline
\end{tabular}


Analysis I.I. Comparison I Mitoxantrone versus placebo: primary outcomes, Outcome I Patients with 6month confirmed disability progression at 2 years.

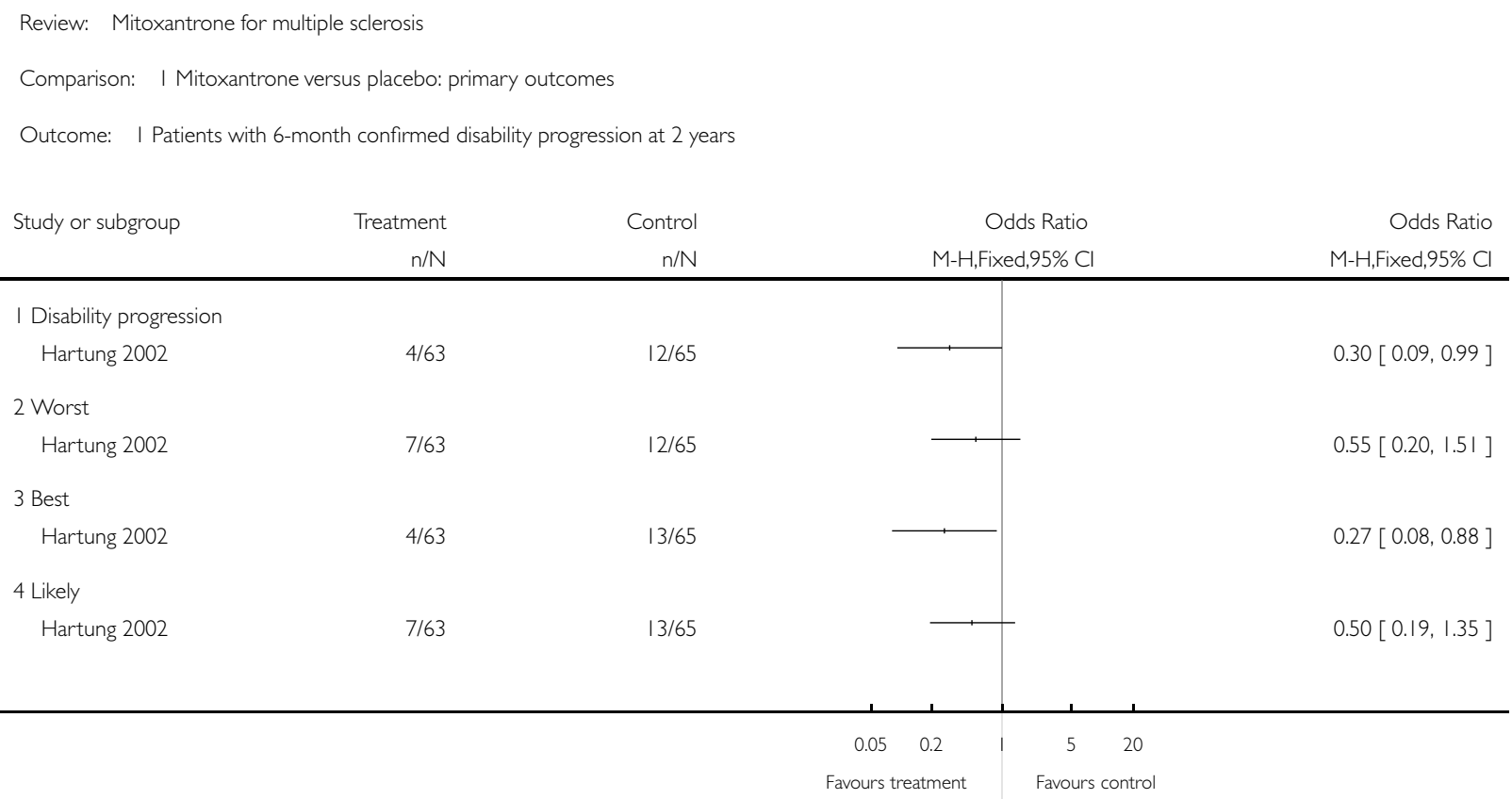


Analysis I.2. Comparison I Mitoxantrone versus placebo: primary outcomes, Outcome 2 Post-hoc analysis: Patients with 3- or 6-month confirmed disability progression.

Review: Mitoxantrone for multiple sclerosis

Comparison: I Mitoxantrone versus placebo: primary outcomes

Outcome: 2 Post-hoc analysis: Patients with 3- or 6-month confirmed disability progression

Study or subgroup Treatment Control Odds Ratio Weight

$\mathrm{n} / \mathrm{N} \quad \mathrm{n} / \mathrm{N}$

n/N M-H,Fixed,95\% Cl

$\mathrm{M}-\mathrm{H}$, Fixed, $95 \% \mathrm{Cl}$

I At I year

Millefiorini 1997

$2 / 27$

$6 / 24$

$100.0 \%$

$0.24[0.04,1.33]$

Subtotal $(95 \%$ CI)

27

24

$100.0 \%$

$0.24[0.04,1.33$ ]

Total events: 2 (Treatment), 6 (Control)

Heterogeneity: not applicable

Test for overall effect: $Z=1.63(P=0.10)$

2 At 2 years

Hartung 2002

Millefiorini 1997

$12 / 65$

$9 / 24$

Subtotal (95\% CI)

90

89

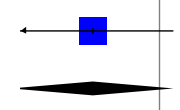

.04, 1.33

Total events: 6 (Treatment), 21 (Control)

Heterogeneity: $\mathrm{Chi}^{2}=0.60, \mathrm{df}=\mathrm{I}(\mathrm{P}=0.44) ; \mathrm{I}^{2}=0.0 \%$

Test for overall effect: $Z=3.03(P=0.0024)$

3 At 2 years - Worst Scenario

$\begin{array}{ll}\text { Hartung } 2002 & 7 / 63 \\ \text { Millefiorini } 1997 & 2 / 27\end{array}$

Subtotal $(\mathbf{9 5 \%}$ CI)

90

Total events: 9 (Treatment), 2 I (Control)

Heterogeneity: $\mathrm{Chi}^{2}=2.07, \mathrm{df}=\mathrm{I}(\mathrm{P}=0.15) ; \mathrm{I}^{2}=52 \%$

Test for overall effect: $Z=2.39(P=0.017)$

4 At 2 years - Best Scenario

$\begin{array}{ll}\text { Hartung } 2002 & 4 / 63 \\ \text { Millefiorini } 1997 & 2 / 27\end{array}$

Subtotal (95\% CI)

90

Total events: 6 (Treatment), 22 (Control)

Heterogeneity: $\mathrm{Ch}^{2}=0.47, \mathrm{df}=\mathrm{I}(\mathrm{P}=0.49) ; \mathrm{I}^{2}=0.0 \%$

Test for overall effect: $Z=3.17(P=0.0015)$

5 At 2 years - Likely Scenario

$\begin{array}{ll}\text { Hartung } 2002 & 7 / 63 \\ \text { Millefiorini } 1997 & \text { 2/27 }\end{array}$

Subtotal (95\% CI)

90

12/65

$9 / 24$

89

$54.3 \%$

$0.55[0.20,1.51]$

$45.7 \%$

$0.13[0.03,0.70]$

13/65

$9 / 24$

89

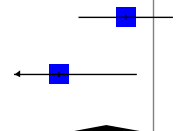

$100.0 \%$

$57.6 \%$

$42.4 \%$

$100.0 \%$

$0.27[0.08,0.88]$

$0.13[0.03,0.70]$

0.21 [ 0.08, 0.55 ]

$56.3 \%$

$0.50[0.19,1.35]$

$43.7 \%$

$0.13[0.03,0.70]$

89

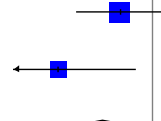

$100.0 \%$

$0.34[0.15,0.78]$

Total events: 9 (Treatment), 22 (Control)

Heterogeneity: $\mathrm{Chi}^{2}=1.80, \mathrm{df}=\mathrm{I}(\mathrm{P}=0.18) ; \mathrm{I}^{2}=44 \%$

Test for overall effect: $Z=2.54(P=0.011)$
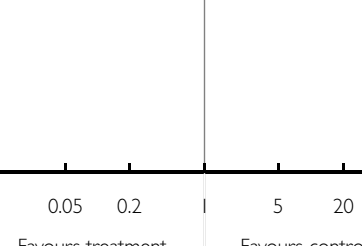

Favours treatment Favours control

Mitoxantrone for multiple sclerosis (Review)

Copyright @ 2013 The Cochrane Collaboration. Published by John Wiley \& Sons, Ltd. 
Analysis I.3. Comparison I Mitoxantrone versus placebo: primary outcomes, Outcome 3 Patients who withdrew from the study because of major side effects of the drug.

\begin{tabular}{|c|c|c|c|c|}
\hline \multicolumn{5}{|c|}{ Review: Mitoxantrone for multiple sclerosis } \\
\hline \multicolumn{5}{|c|}{ Comparison: I Mitoxantrone versus placebo: primary outcomes } \\
\hline \multicolumn{5}{|c|}{ Outcome: 3 Patients who withdrew from the study because of major side effects of the drug } \\
\hline \multirow[t]{2}{*}{ Study or subgroup } & Treatment & Control & \multirow{2}{*}{$\begin{array}{r}\text { Odds Ratio } \\
\text { M-H,Fixed,95\% Cl }\end{array}$} & Odds Ratio \\
\hline & $\mathrm{n} / \mathrm{N}$ & $\mathrm{n} / \mathrm{N}$ & & M-H,Fixed,95\% Cl \\
\hline Edan 1997 & $0 / 21$ & $0 / 21$ & & $0.0[0.0,0.0]$ \\
\hline Millefiorini 1997 & $0 / 27$ & $0 / 24$ & & $0.0[0.0,0.0]$ \\
\hline Hartung 2002 & $5 / 63$ & $2 / 65$ & H & $2.72[0.51,14.54]$ \\
\hline Total $(95 \% \mathrm{CI})$ & 111 & 110 & & $2.72[0.51,14.54]$ \\
\hline \multicolumn{5}{|c|}{ Total events: 5 (Treatment), 2 (Control) } \\
\hline \multicolumn{5}{|c|}{ Heterogeneity: $\mathrm{Ch}^{2}=0.0, \mathrm{df}=0(\mathrm{P}=1.00) ; \mathrm{I}^{2}=0.0 \%$} \\
\hline \multicolumn{5}{|c|}{ Test for overall effect: $Z=1.17(P=0.24)$} \\
\hline \multicolumn{5}{|c|}{ Test for subgroup differences: Not applicable } \\
\hline
\end{tabular}


Analysis 2.1. Comparison 2 Mitoxantrone versus placebo: secondary outcomes, Outcome I Patients with no relapses at 6 months/I year.

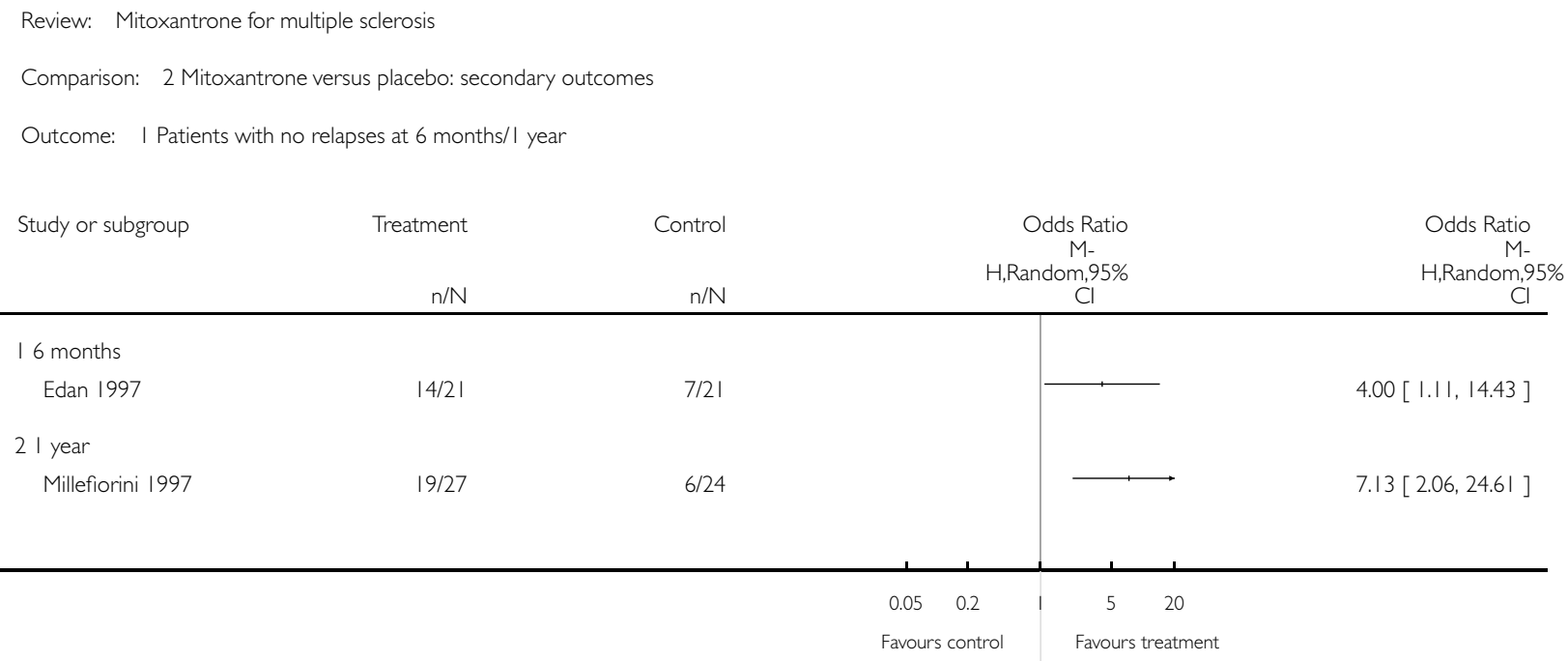


Analysis 2.2. Comparison 2 Mitoxantrone versus placebo: secondary outcomes, Outcome 2 Mean change in disability (EDSS).

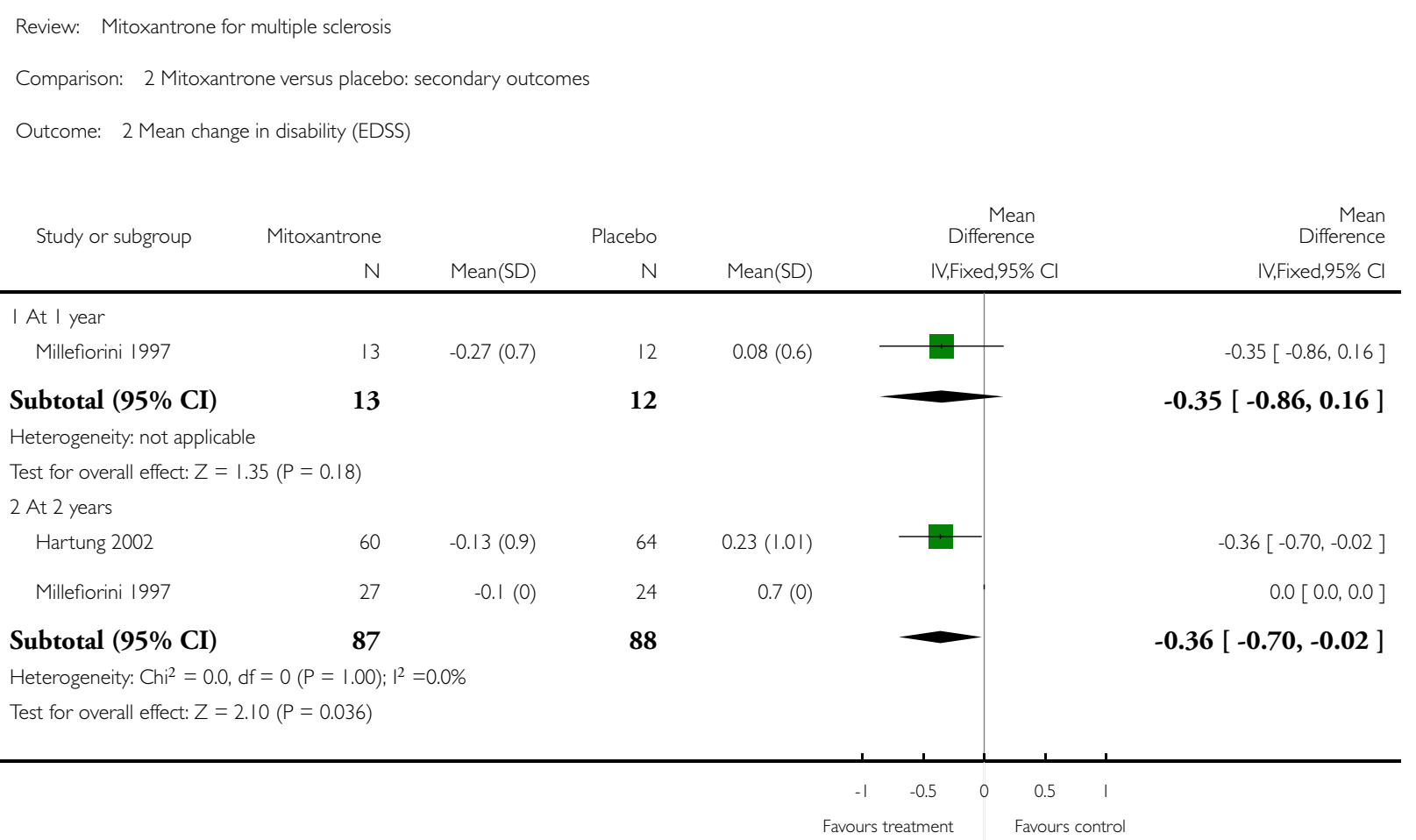


Analysis 2.3. Comparison 2 Mitoxantrone versus placebo: secondary outcomes, Outcome 3 Patients with no relapses at 2 years.

Review: Mitoxantrone for multiple sclerosis

Comparison: 2 Mitoxantrone versus placebo: secondary outcomes

Outcome: 3 Patients with no relapses at 2 years

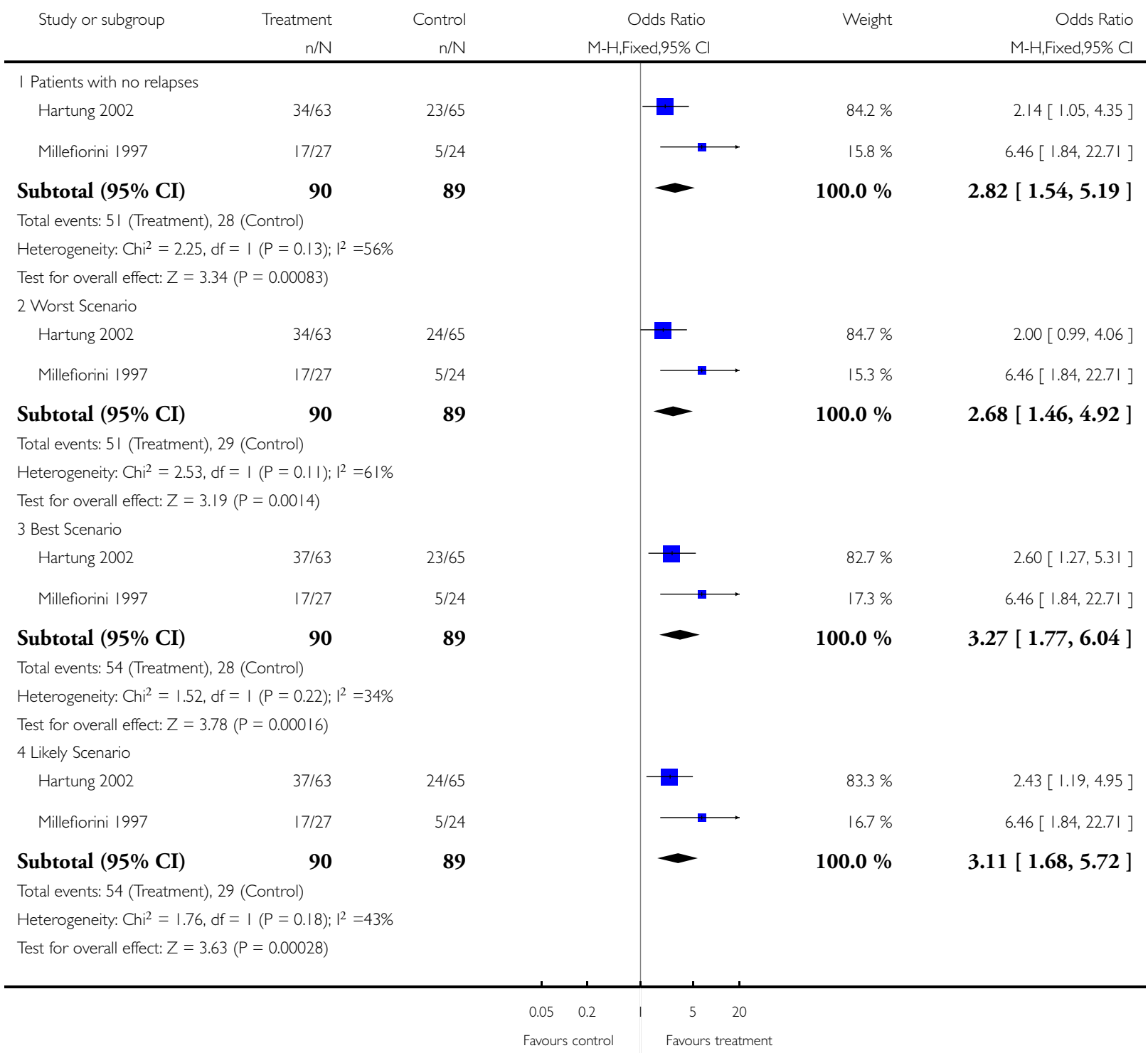

Mitoxantrone for multiple sclerosis (Review)

Copyright @ 2013 The Cochrane Collaboration. Published by John Wiley \& Sons, Ltd. 
Analysis 2.4. Comparison 2 Mitoxantrone versus placebo: secondary outcomes, Outcome 4 Annualized relapse rate.

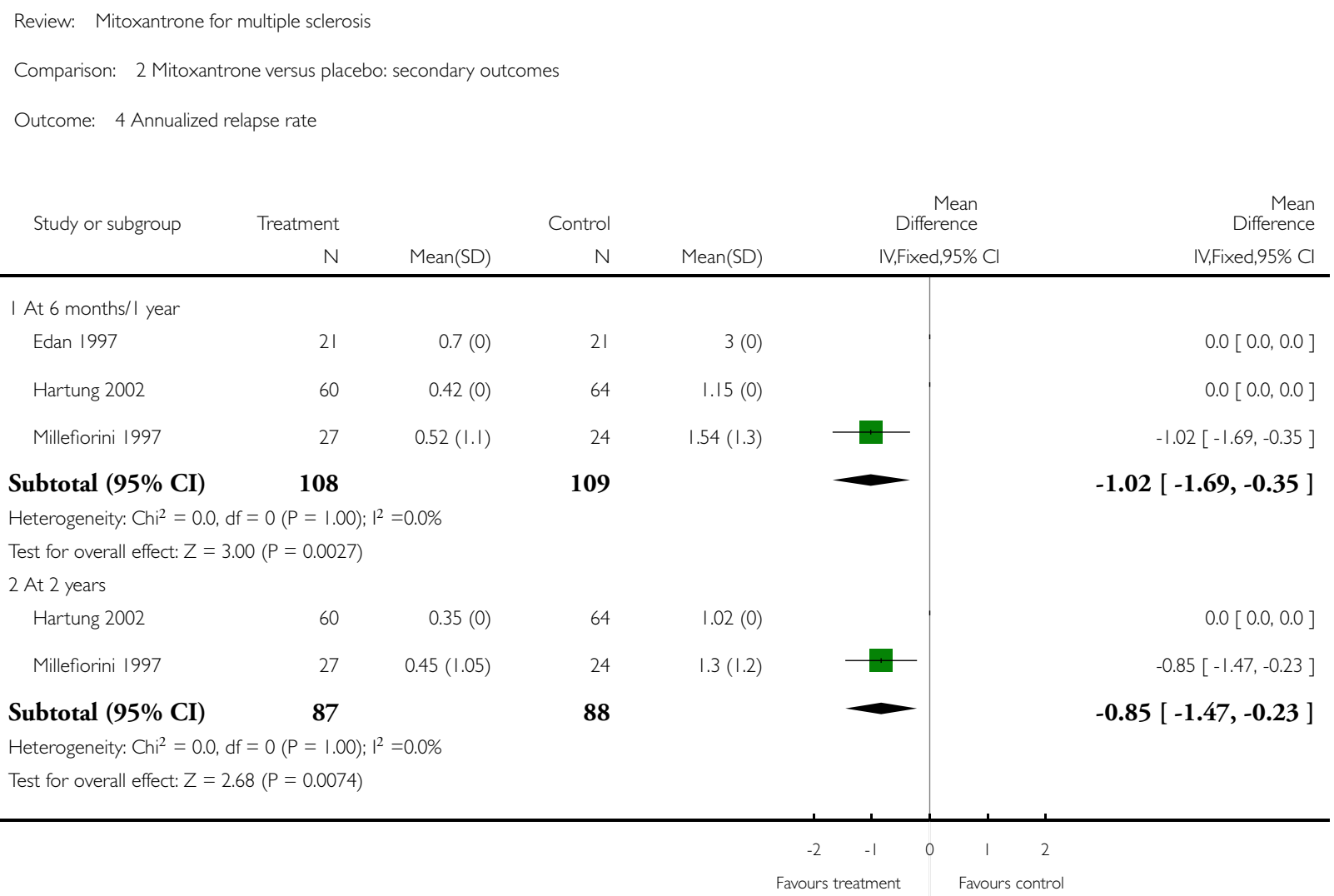


Analysis 2.5. Comparison 2 Mitoxantrone versus placebo: secondary outcomes, Outcome 5 Number of MRI active lesions.

Review: Mitoxantrone for multiple sclerosis

Comparison: 2 Mitoxantrone versus placebo: secondary outcomes

Outcome: 5 Number of MRI active lesions

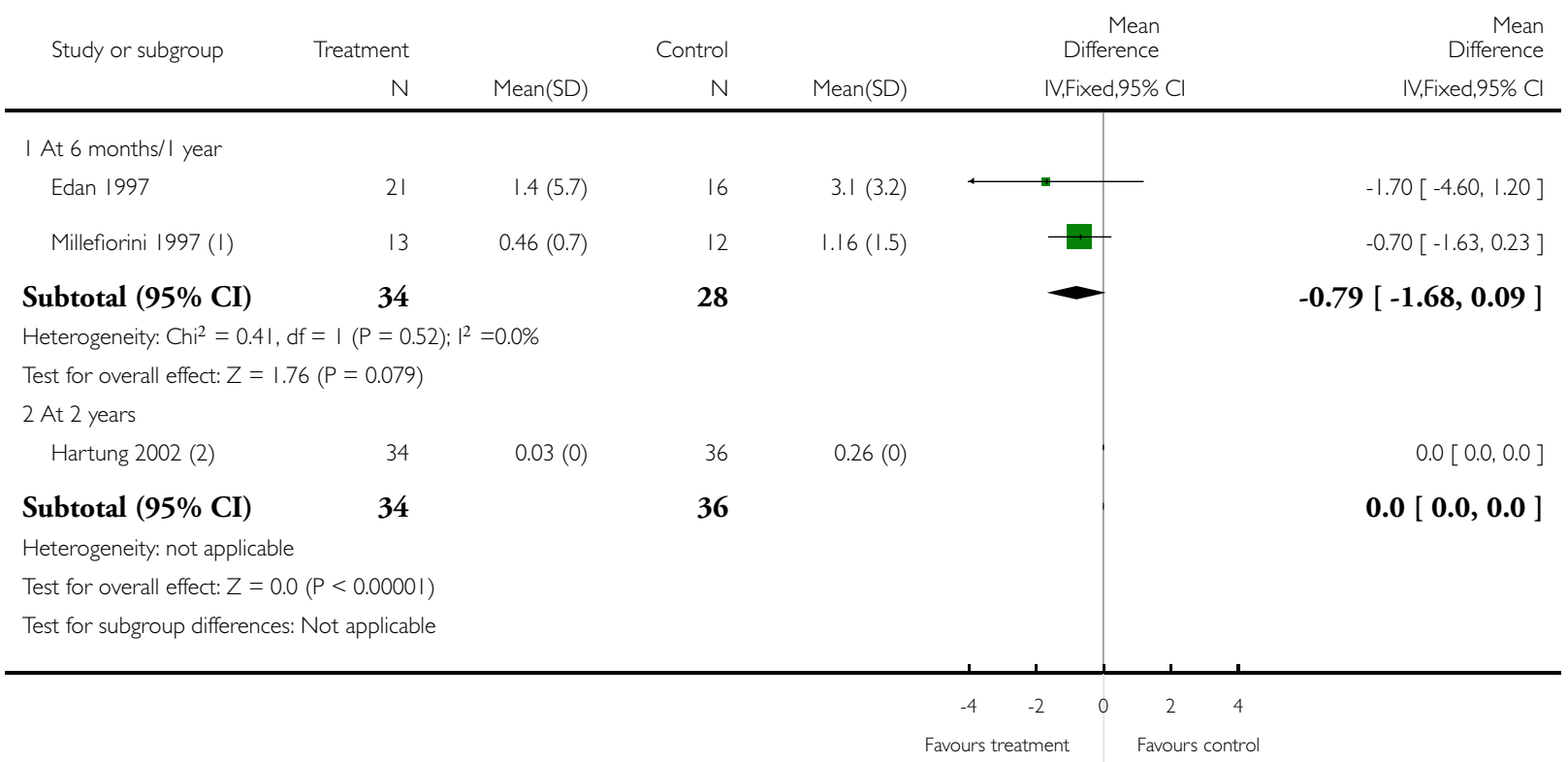

( I) Data were retrieved from contact with study authors

(2) Data were retrieved from contact with study authors 
Analysis 2.6. Comparison 2 Mitoxantrone versus placebo: secondary outcomes, Outcome 6 Number of patients with active lesions.

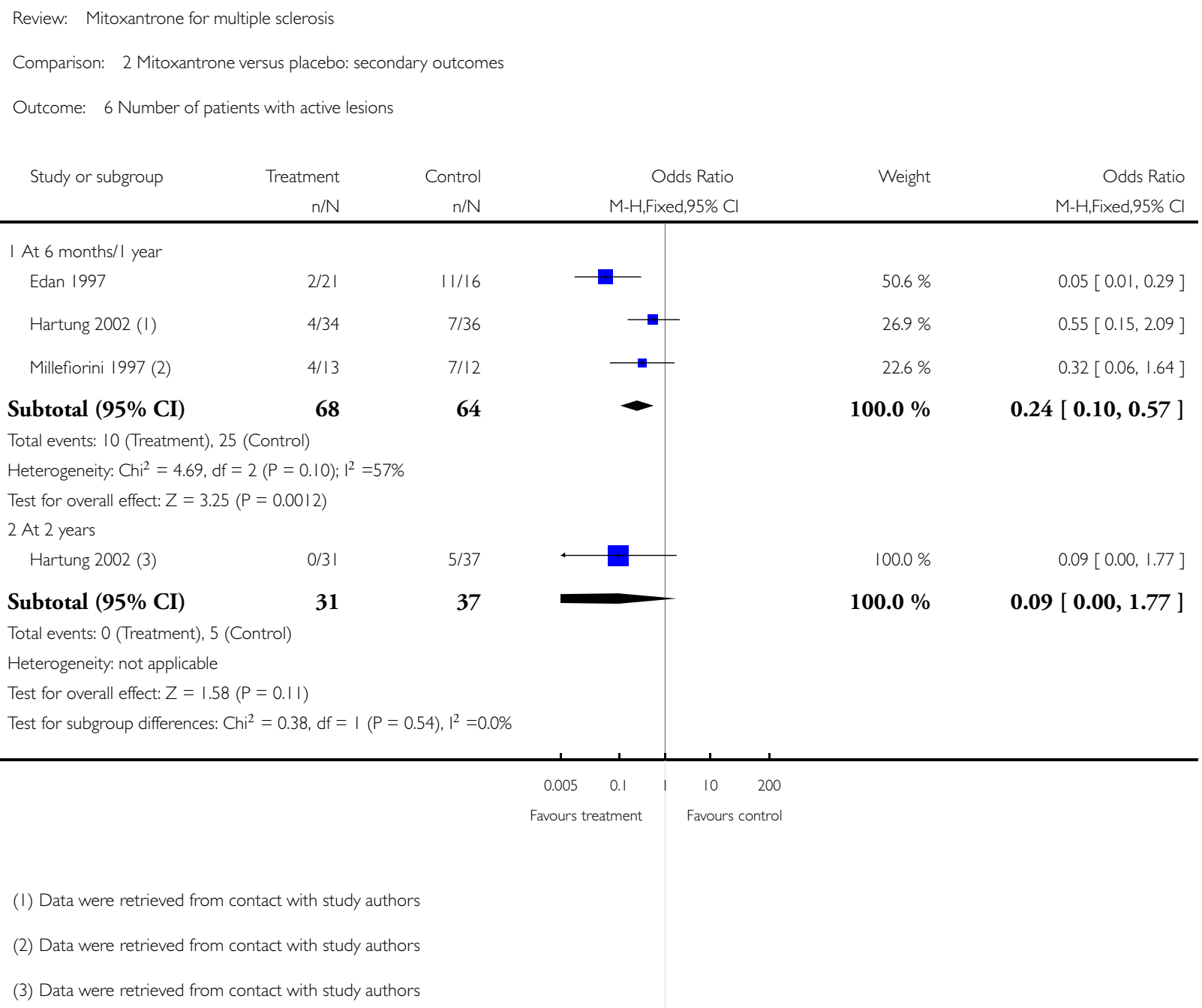


Analysis 3.I. Comparison 3 Mitoxantrone versus placebo: adverse events, Outcome I Amenorrea.

Review: Mitoxantrone for multiple sclerosis

Comparison: 3 Mitoxantrone versus placebo: adverse events

Outcome: I Amenorrea

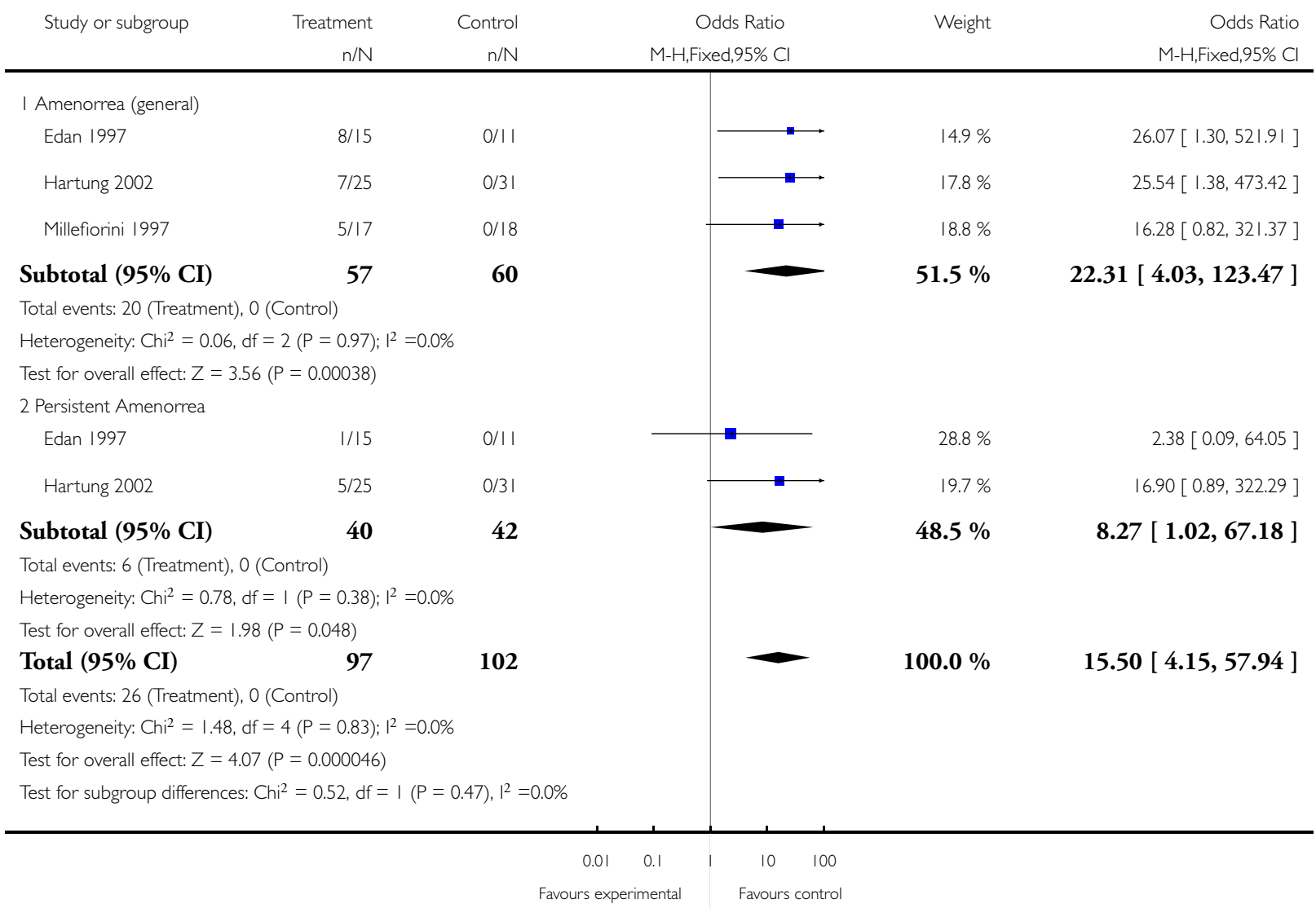


Analysis 3.2. Comparison 3 Mitoxantrone versus placebo: adverse events, Outcome 2 Nausea/Vomiting.

Review: Mitoxantrone for multiple sclerosis

Comparison: 3 Mitoxantrone versus placebo: adverse events

Outcome: 2 Nausea/Nomiting

\begin{tabular}{|c|c|c|c|c|c|}
\hline \multirow[t]{2}{*}{ Study or subgroup } & Treatment & Control & Odds Ratio & Weight & Odds Ratio \\
\hline & $\mathrm{n} / \mathrm{N}$ & $\mathrm{n} / \mathrm{N}$ & M-H,Fixed,95\% Cl & & M-H,Fixed,95\% Cl \\
\hline Edan 1997 & $6 / 21$ & $0 / 21$ & & $9.3 \%$ & $18.03[0.94,344.40]$ \\
\hline Hartung 2002 & $47 / 62$ & $13 / 64$ & & $81.5 \%$ & $12.29[5.30,28.53]$ \\
\hline Millefiorini 1997 & $9 / 27$ & $0 / 24$ & $\longrightarrow$ & $9.2 \%$ & $25.16[1.37,460.60]$ \\
\hline Total $(95 \% \mathrm{CI})$ & 110 & 109 & & $100.0 \%$ & $14.01[6.36,30.85]$ \\
\hline
\end{tabular}

Total events: 62 (Treatment), 13 (Control)

Heterogeneity: Chi $^{2}=0.28, d f=2(P=0.87) ; 1^{2}=0.0 \%$

Test for overall effect: $Z=6.55(P<0.00001)$

Test for subgroup differences: Not applicable

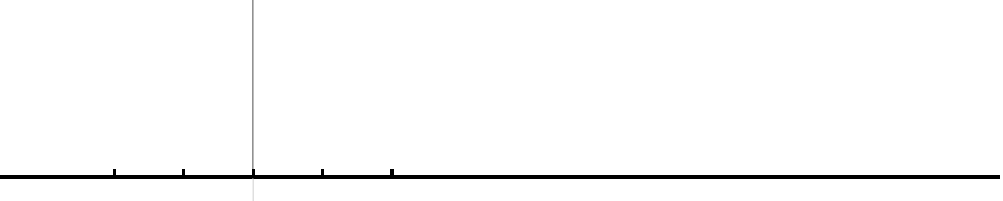

Favours experimental Favours control

Analysis 3.3. Comparison 3 Mitoxantrone versus placebo: adverse events, Outcome 3 Alopecia.

Review: Mitoxantrone for multiple sclerosis

Comparison: 3 Mitoxantrone versus placebo: adverse events

Outcome: 3 Alopecia

\begin{tabular}{|c|c|c|c|c|c|}
\hline \multirow[t]{2}{*}{ Study or subgroup } & Treatment & Control & Odds Ratio & Weight & Odds Ratio \\
\hline & $\mathrm{n} / \mathrm{N}$ & $\mathrm{n} / \mathrm{N}$ & M-H,Fixed,95\% Cl & & M-H,Fixed,95\% Cl \\
\hline Edan 1997 & $7 / 21$ & $0 / 21$ & $\longrightarrow$ & $3.9 \%$ & $22.24[1.18,420.36]$ \\
\hline Hartung 2002 & $38 / 62$ & $20 / 64$ & & $91.0 \%$ & $3.48[1.67,7.27]$ \\
\hline Millefiorini 1997 & $5 / 27$ & $0 / 24$ & & $5.1 \%$ & $11.98[0.63,229.09]$ \\
\hline Total (95\% CI) & 110 & 109 & & $100.0 \%$ & $4.65[2.37,9.12]$ \\
\hline
\end{tabular}

Total events: 50 (Treatment), 20 (Control)

Heterogeneity: $\mathrm{Chi}^{2}=2.08, \mathrm{df}=2(\mathrm{P}=0.35) ; \mathrm{I}^{2}=4 \%$

Test for overall effect: $Z=4.47(P<0.00001)$

Test for subgroup differences: Not applicable

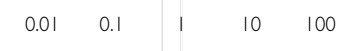

Favours experimental Favours control

Copyright $\odot 2013$ The Cochrane Collaboration. Published by John Wiley \& Sons, Ltd. 
Analysis 3.4. Comparison 3 Mitoxantrone versus placebo: adverse events, Outcome 4 Urinary tract Infections.

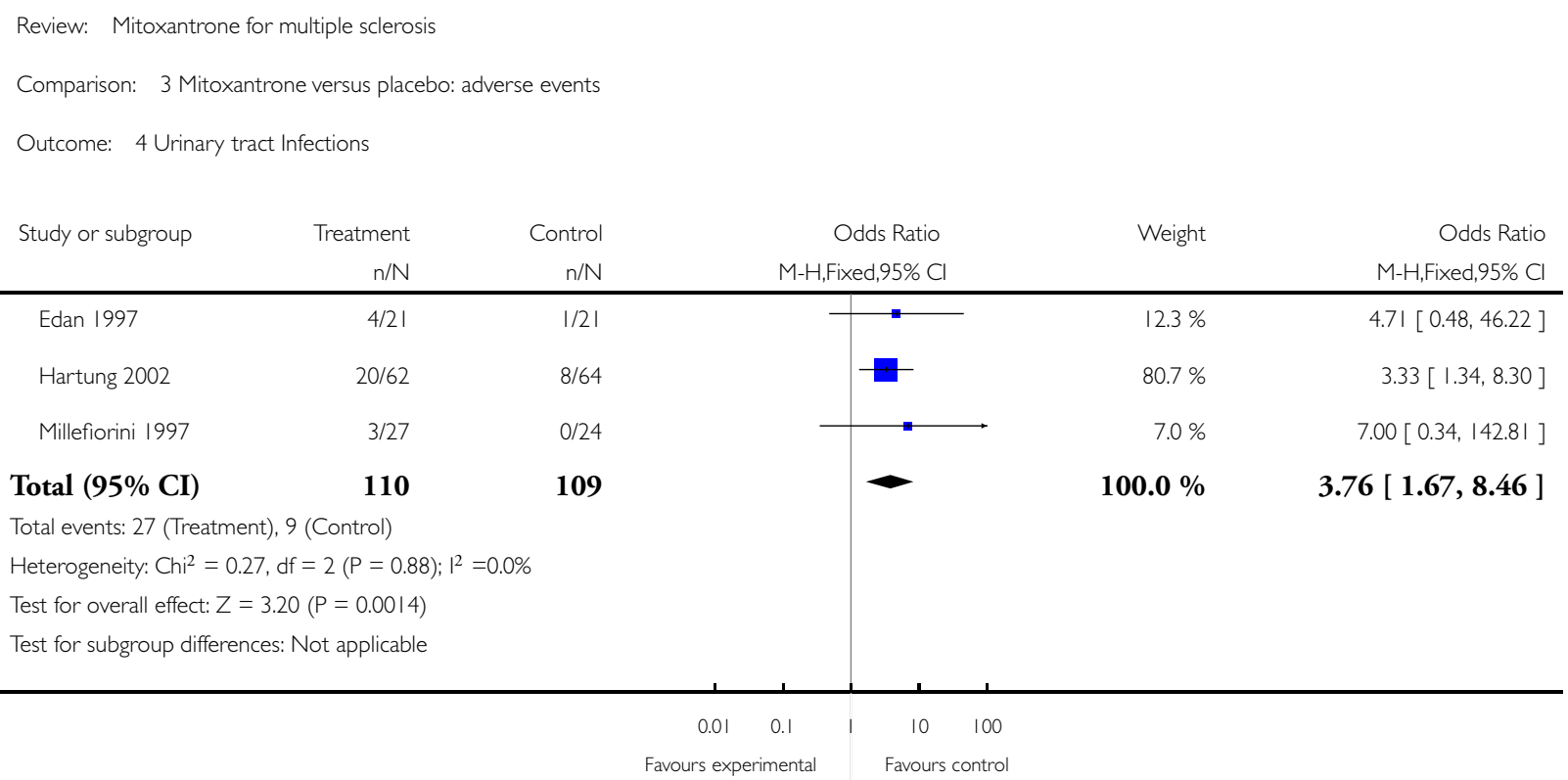


Analysis 3.5. Comparison 3 Mitoxantrone versus placebo: adverse events, Outcome 5 Respiratory tract infections.

\begin{tabular}{|c|c|c|c|c|c|}
\hline \multicolumn{6}{|c|}{ Review: Mitoxantrone for } \\
\hline \multicolumn{6}{|c|}{ Comparison: 3 Mitoxantrone versus placebo: adverse events } \\
\hline \multicolumn{6}{|c|}{ Outcome: 5 Respiratory tract infections } \\
\hline \multirow[t]{2}{*}{ Study or subgroup } & Treatment & Control & Odds Ratio & Weight & Odds Ratio \\
\hline & $\mathrm{n} / \mathrm{N}$ & $\mathrm{n} / \mathrm{N}$ & M-H,Fixed,95\% Cl & & M-H,Fixed,95\% Cl \\
\hline Edan 1997 & $5 / 21$ & $2 / 21$ & $\square$ & $8.9 \%$ & $2.97[0.51,17.42]$ \\
\hline Hartung 2002 & $33 / 62$ & $33 / 64$ & & $88.3 \%$ & $1.07[0.53,2.15]$ \\
\hline Millefiorini 1997 & $2 / 27$ & 0/24 & 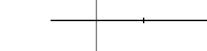 & $2.8 \%$ & $4.80[0.22,105.22]$ \\
\hline Total $(95 \% \mathrm{CI})$ & 110 & 109 & - & $100.0 \%$ & $1.34[0.72,2.50]$ \\
\hline \multicolumn{6}{|c|}{ Total events: 40 (Treatment), 35 (Control) } \\
\hline \multicolumn{6}{|c|}{ Heterogeneity: $\mathrm{Chi}^{2}=1.84, \mathrm{df}=2(\mathrm{P}=0.40) ; \mathrm{I}^{2}=0.0 \%$} \\
\hline \multicolumn{6}{|c|}{ Test for overall effect: $Z=0.93(P=0.35)$} \\
\hline \multicolumn{6}{|c|}{ Test for subgroup differences: Not applicable } \\
\hline
\end{tabular}


Analysis 3.6. Comparison 3 Mitoxantrone versus placebo: adverse events, Outcome 6 Headhache.

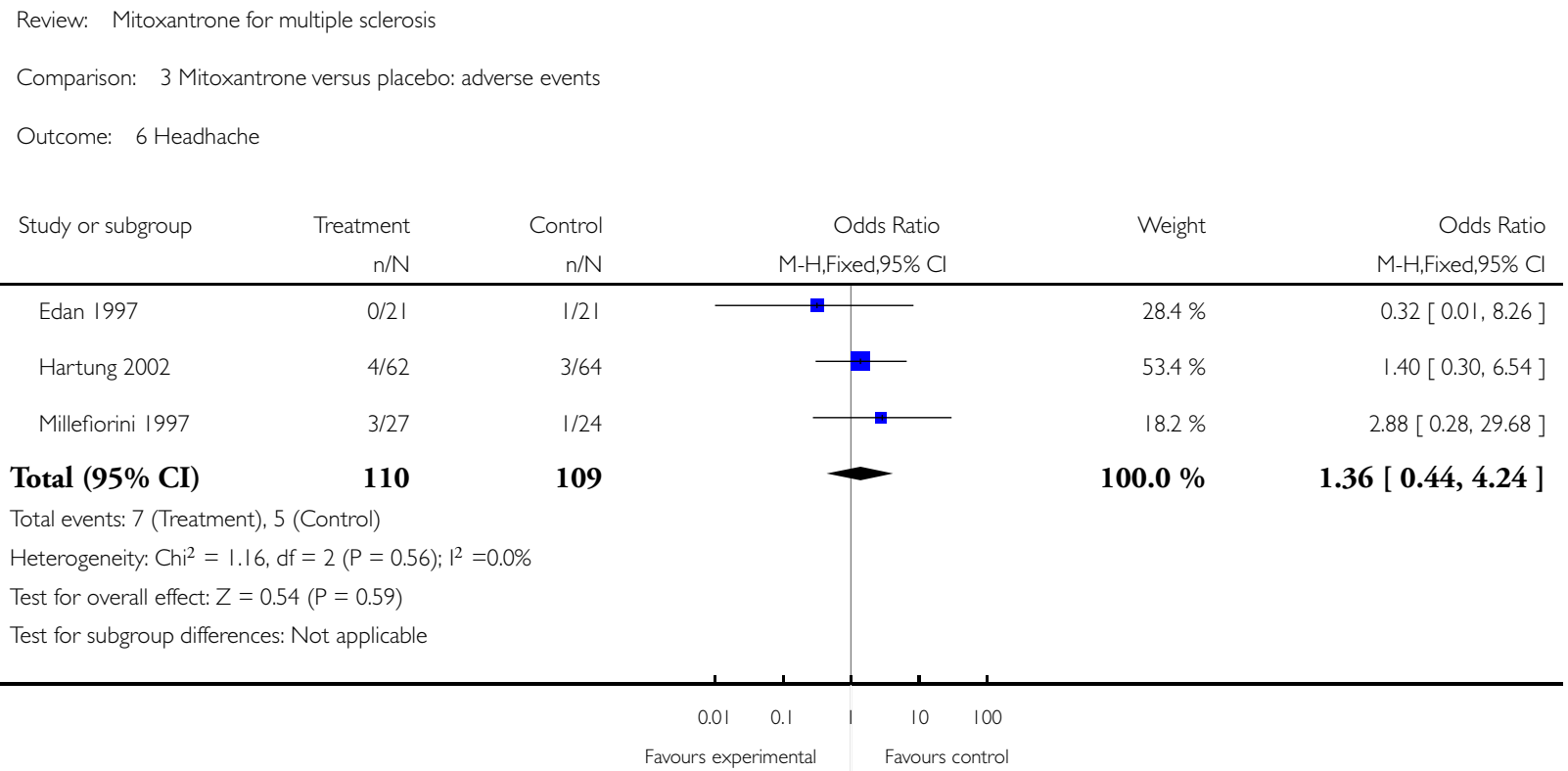

\section{Analysis 4.I. Comparison 4 Mitoxantrone versus placebo: abnormal laboratory values, Outcome I Leucopenia.}

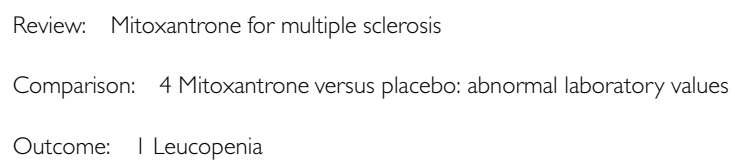

\begin{tabular}{|c|c|c|c|c|c|}
\hline \multirow{2}{*}{ Study or subgroup } & Treatment & Control & Odds Ratio & Weight & Odds Ratio \\
\hline & $n / N$ & $n / N$ & M-H,Fixed, $95 \%$ Cl & & M-H,Fixed,95\% Cl \\
\hline Edan 1997 & $2 / 21$ & $0 / 21$ & $=$ & $52.9 \%$ & $5.51[0.25,122.08]$ \\
\hline Hartung 2002 & $12 / 62$ & $0 / 64$ & $\longrightarrow$ & $47.1 \%$ & $31.93[1.85,552.34]$ \\
\hline
\end{tabular}

Total $(\mathbf{9 5 \%}$ CI)

83

85

$100.0 \%$

$17.95[2.35,137.00]$

Total events: 14 (Treatment), 0 (Control)

Heterogeneity: Chi $^{2}=0.71, \mathrm{df}=\mathrm{I}(\mathrm{P}=0.40) ; \mathrm{I}^{2}=0.0 \%$

Test for overall effect: $Z=2.79(P=0.0053)$

Test for subgroup differences: Not applicable

Favours experimental Favours control

Copyright $\odot 2013$ The Cochrane Collaboration. Published by John Wiley \& Sons, Ltd. 
Analysis 4.2. Comparison 4 Mitoxantrone versus placebo: abnormal laboratory values, Outcome 2 Anemia.

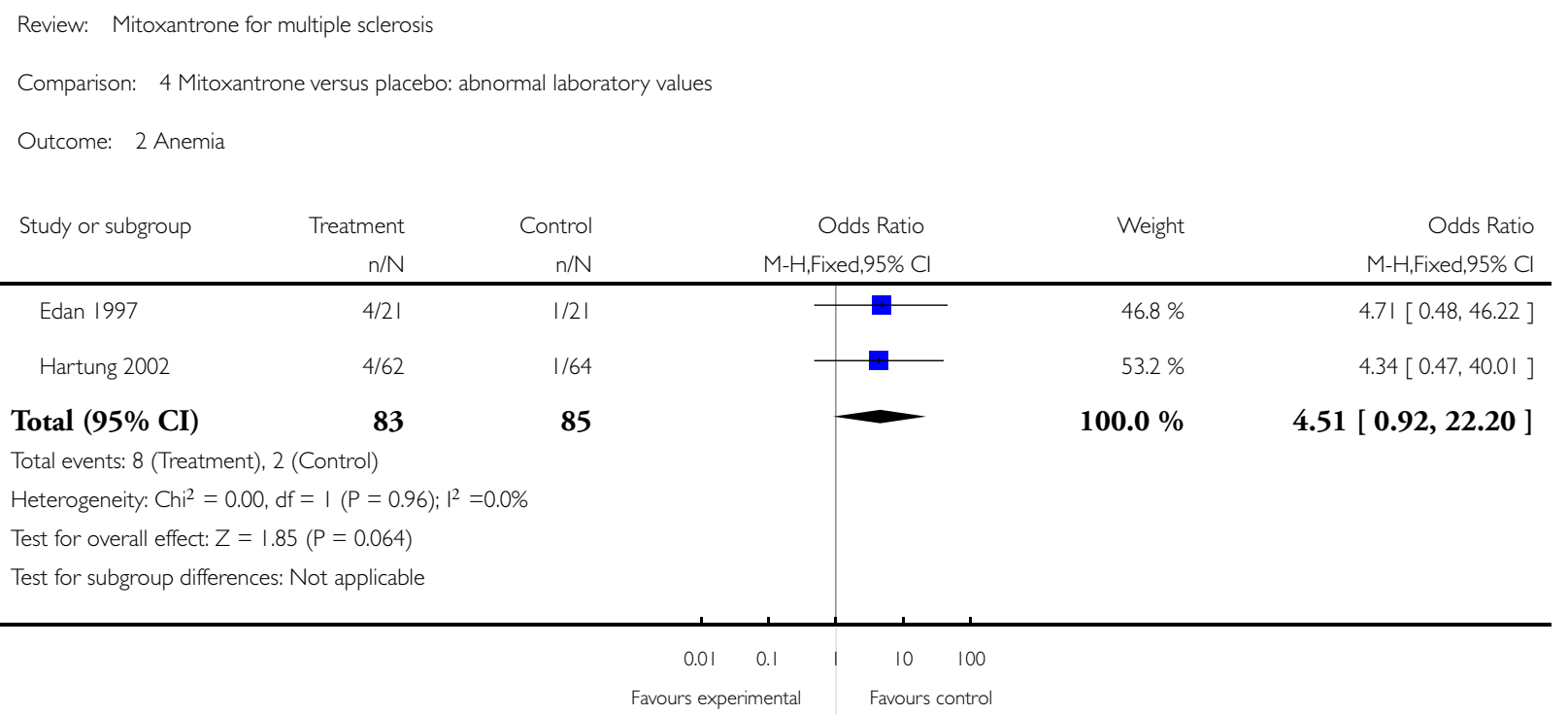

\section{ADDITIONAL TABLES}

Table 1. Number and reasons of withdrawn or loss to follow-up in included studies

\begin{tabular}{|c|c|c|c|c|c|c|c|}
\hline Studies & $\begin{array}{l}\text { Withdrawn } \\
\text { or Lost to fol- } \\
\text { low-up on the } \\
\text { total of pa- } \\
\text { tients }\end{array}$ & $\begin{array}{l}\text { Major side ef- } \\
\text { fects }\end{array}$ & $\begin{array}{l}\text { Minor side ef- } \\
\text { fects }\end{array}$ & Refusal & $\begin{array}{l}\text { Disease pro- } \\
\text { gression }\end{array}$ & Others & Total \\
\hline Edan & $\begin{array}{l}5 / 42(11.9 \%) \\
\text { in placebo arm }\end{array}$ & 0 & 0 & 0 & Placebo: 5 & 0 & Placebo: 5 \\
\hline Millefiorini & $0 / 51$ & 0 & 0 & 0 & 0 & 0 & 0 \\
\hline Hartung & $\begin{array}{ll}33 / 128 & (25 . \\
8 \%) & \\
- & M X\end{array}$ & $\begin{array}{l}\text { - MX } 12 \mathrm{mg} / \\
\mathrm{m}^{2}: 5 \text { partici- } \\
\text { pants ( } 1 \text { major }\end{array}$ & 0 & $\begin{array}{l}\text { MX } 12 \mathrm{mg} / \mathrm{m} \\
{ }^{2}: 2 ; \\
\text { Placebo: } 6\end{array}$ & $\begin{array}{l}\text { MX } 12 \mathrm{mg} / \mathrm{m} \\
{ }^{2}: 4 ; \\
\text { Placebo: } 8\end{array}$ & $\begin{array}{l}\text { MX } 12 \mathrm{mg} / \mathrm{m} \\
{ }^{2}: 4\end{array}$ & $\begin{array}{l}\text { MX } 12 \mathrm{mg} / \mathrm{m} \\
{ }^{2}: 15 ;\end{array}$ \\
\hline
\end{tabular}


Table 1. Number and reasons of withdrawn or loss to follow-up in included studies (Continued)

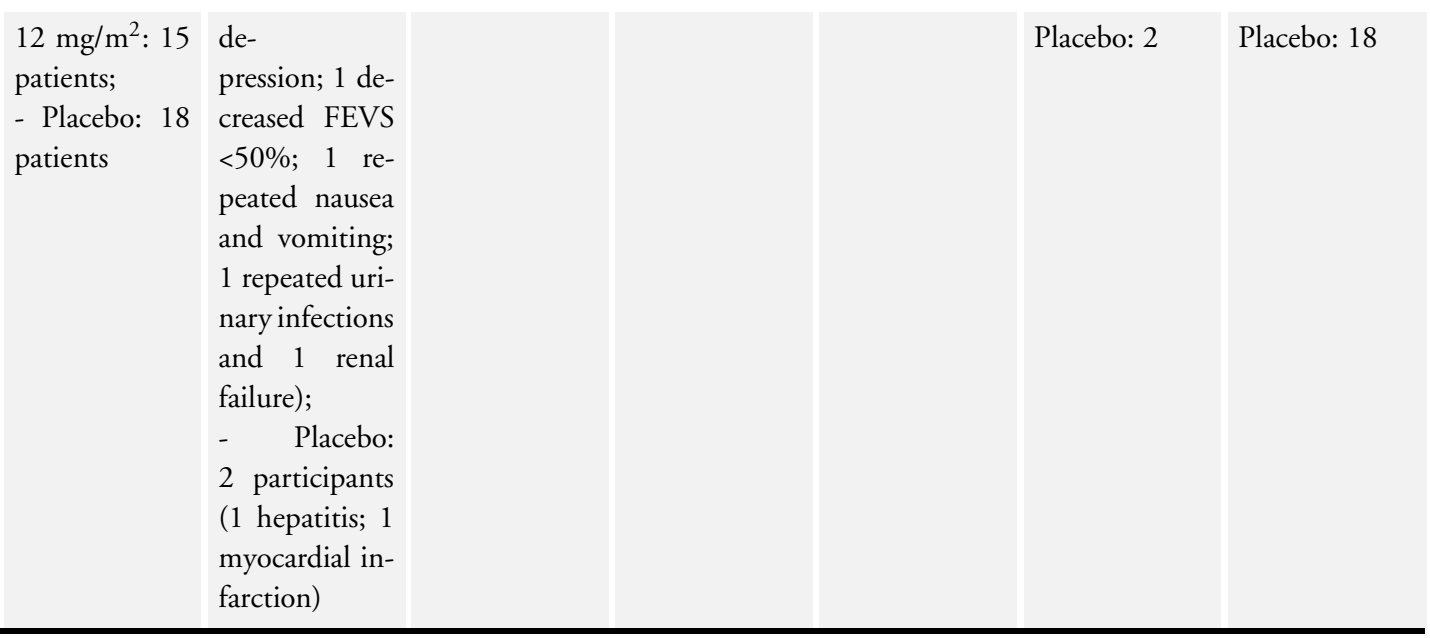

Table 2. Mitoxantrone dosage adjustment

\begin{tabular}{l|l|l|l|l}
\hline Dose to be given & $\mathbf{1 0 0} \%$ & $\mathbf{9 0 \%}$ & $\mathbf{7 5 \%}$ & Stop \\
\hline $\begin{array}{l}\text { If: Leucocytes }(\mathrm{x} 1000 / \\
\mathrm{ml})\end{array}$ & $>=4$ & $3-3.99$ & $2-2.99$ & $<2$ \\
\hline $\begin{array}{l}\text { If: Granulocytes }(\mathrm{x} 1000 / \\
\mathrm{ml})\end{array}$ & $>=2$ & $1.5-1.99$ & $1-1.49$ & $<1$ \\
\hline \begin{tabular}{l} 
If: Platelets $(\mathrm{x} 1000 / \mathrm{ml})$ \\
\hline
\end{tabular} & $>=100$ & $75-99$ & $50-74$ & $<50$ \\
\hline
\end{tabular}

\section{A P P E N D I CES}

\section{Appendix I. Keywords}

\{novantrone\} OR \{novantron\} OR \{pralifan\} OR \{mitoxantrone\} 


\section{WHAT'S NEW}

Last assessed as up-to-date: 30 May 2013.

\begin{tabular}{lll}
\hline Date & Event & Description \\
\hline 30 May 2013 & Review declared as stable & $\begin{array}{l}\text { From 2005, no new RCTs matched our inclusion criteria. To our knowledge, no } \\
\text { more study versus placebo started or are ongoing }\end{array}$ \\
\hline 23 May 2013 & New search has been performed & Search was re-run. \\
\hline
\end{tabular}

\section{H I S T O R Y}

Protocol first published: Issue 2, 2000

Review first published: Issue 4, 2005

\begin{tabular}{|c|c|c|}
\hline Date & Event & Description \\
\hline 30 August 2012 & $\begin{array}{l}\text { New citation required but conclusions have not } \\
\text { changed }\end{array}$ & $\begin{array}{l}\text { No new trials have been identified. } \\
\text { Risk of bias tables and a secondary outcome have been } \\
\text { added. } \\
\text { A previous included trial was excluded from the update } \\
\text { of this review because it did not fulfil our inclusion } \\
\text { criteria } \\
\text { The terms of comparison have been better defined. } \\
\text { The text has been amended throughout. }\end{array}$ \\
\hline 18 June 2012 & New search has been performed & Search was re-run. \\
\hline 12 November 2008 & Amended & $\begin{array}{l}\text { Abstract, declaration of Interest and Next stage ex- } \\
\text { pected. }\end{array}$ \\
\hline 25 August 2008 & Amended & Converted to new review format. \\
\hline
\end{tabular}

\section{CONTRIBUTIONSOFAUTHORS}

F Martinelli Boneschi and M Rovaris ideated the project.

M Rovaris, F Martinelli Boneschi and R Capra selected and reviewed the articles.

F Martinelli Boneschi wrote the final text.

M Rovaris, R Capra and G Comi supervised the review.

F Martinelli Boneschi and L Vacchi managed the review update: they assessed the relevance and quality of the articles found; abstracted data; re-checked the analysis, the results and conclusion.

F Martinelli Boneschi, L Vacchi, M Rovaris, R Capra and G Comi reviewed the text. 


\section{DECLARATIONSOF INTEREST}

The review was assembled, analysed and reported independently of any pharmaceutical company.

Dr Martinelli Boneschi received personal compensations for activities from BiogenIdec Italy, Dompè-Biogen Italy, Merck-Serono.

Dr Rovaris has received personal compensations for activities with: TEVA Pharmaceutical Industries, Novartis Pharma, Sanofi-Aventis Italy and Biogenidec Italy.

Dr Capra received consulting fees from Novartis, Merck Serono, BiogenIdec and lecture fees from Bayer, BiogenIdec, Dompé, Genzyme and Sanofi-Aventis

Prof Comi has received grants and honoraria for his consulting activity from Teva, Merck-Serono, Biogenidec, Sanofi-Aventis Italia and Schering.

Dr Vacchi has no conflict of interest.

\section{DIFFERENCES BETWEEN PROTOCOLAND REVIEW}

Review team changed between protocol and review.

Doctor Vacchi joined the team for the 2013 update.

In the 2013 update (Martinelli Boneschi 2013), no new RCTs were included, but the exclusion of one trial previously included in this review (Van de Wyngaert 2001) caused a partial revision of analyses and discussion. The review team decided to exclude this trial because it didn't entirely meet the inclusion criteria (absence of a clean placebo group, treated with steroids).

The terms of comparison have been better defined (MX versus placebo or MX plus steroids treatment versus placebo plus steroids).

A secondary outcome ('Abnormal laboratory values') has been added.

Further, due to the new Cochrane rules, an exhaustive description of risk of bias has been added.

Since the last research strategies of the literature did not reveal any new references of that could meet the inclusion criteria, the current review can be considered as final.

\section{NDEX TERMS}

\section{Medical Subject Headings (MeSH)}

Disease Progression; Immunosuppressive Agents [adverse effects; *therapeutic use]; Mitoxantrone [adverse effects; *therapeutic use]; Multiple Sclerosis [drug therapy]; Multiple Sclerosis, Chronic Progressive [*drug therapy]; Multiple Sclerosis, Relapsing-Remitting [*drug therapy]; Randomized Controlled Trials as Topic

\section{MeSH check words}

Humans

Mitoxantrone for multiple sclerosis (Review) 